\title{
Large neotheropods from the Upper Triassic of North America and the early evolution of large theropod body sizes
}

\author{
Christopher T. Griffin \\ Department of Geosciences, Virginia Tech, Blacksburg, Virginia 24061, USA <ctgriff@ vt.edu>
}

\begin{abstract}
Large body sizes among nonavian theropod dinosaurs is a major feature in the evolution of this clade, with theropods reaching greater sizes than any other terrestrial carnivores. However, the early evolution of large body sizes among theropods is obscured by an incomplete fossil record, with the largest Triassic theropods represented by only a few individuals of uncertain ontogenetic stage. Here I describe two neotheropod specimens from the Upper Triassic Bull Canyon Formation of New Mexico and place them in a broader comparative context of early theropod anatomy. These specimens possess morphologies indicative of ontogenetic immaturity (e.g., absence of femoral bone scars, lack of co-ossification between the astragalus and calcaneum), and phylogenetic analyses recover these specimens as early-diverging neotheropods in a polytomy with other early neotheropods at the base of the clade. Ancestral state reconstruction for body size suggests that the ancestral theropod condition was small ( $240 \mathrm{~mm}$ femur length), but the ancestral neotheropod was larger ( 300-340 mm femur length), with coelophysoids experiencing secondary body size reduction, although this is highly dependent on the phylogenetic position of a few key taxa. Theropods evolved large body sizes before the Triassic-Jurassic extinction, as hypothesized in most other ancestral state reconstructions of theropod body sizes, but remained rare relative to smaller theropods until the Jurassic.
\end{abstract}

\section{Introduction}

The evolution of large body sizes among theropod dinosaurs, a clade that includes some of the largest known terrestrial carnivores, is a major feature of the history of this group, influencing growth dynamics (Erickson et al., 2004; Carrano, 2006), biomechanics (Day et al., 2002; Preuschoft et al., 2011), ecology (Farlow and Pianka, 2002; Benson et al., 2014), and evolutionary trends (Carrano, 2006; Sereno et al., 2009; Brusatte et al., 2010a; Benson et al., 2014, 2018). In earlier studies, theropods have often been thought to have remained almost exclusively small-bodied (1-2 m body length, $200 \mathrm{~mm}$ femoral length, $\sim 10 \mathrm{~kg}$ ) throughout most of the Triassic (e.g., Olsen et al., 2002; Langer and Benton, 2006; Brusatte et al., 2010b), and the early evolution of large body sizes (roughly Dilophosaurussized, $\sim 500 \mathrm{~mm}$ femoral length, $\sim 350 \mathrm{~kg}$ ) in theropods has been historically less well understood relative to that of later Mesozoic forms following the Triassic and early Jurassic, when truly gigantic body sizes were eventually reached (e.g., Tyrannosaurus rex, 7,700 kg; Benson et al., 2017). Although footprint data have been used to suggest that there was a sharp increase in the maximum body size of theropods only at the beginning of the Jurassic (Olsen et al., 2002), more recently reconstructed ancestral states of theropod body sizes in the Triassic suggest that theropods larger than the typical coelophysoid size ( 200-230 mm femoral length, $\sim 10 \mathrm{~kg}$ ) evolved prior to the Early Jurassic (Irmis, 2011; Benson et al., 2012, 2014, 2018; Turner and Nesbitt, 2013), although most of these reconstructed body sizes are within the size range of the largest Triassic theropod trackmakers from Olsen and colleagues' (2002) study.
Although few body fossils of relatively large-bodied theropods are known from the Late Triassic, these specimens (e.g., PULR 076, HMN MB.R.2175, UCM 47721) represent skeletally immature individuals that would have reached even larger body sizes than those of their known skeletal remains (Griffin and Nesbitt, in press), further challenging the hypothesis that theropods experienced a dramatic increase in maximum body size at the onset of the Early Jurassic. All this suggests that although they were rare, large-bodied theropods were present in the Late Triassic and their replacement of nondinosaurian reptiles as the largest terrestrial carnivores was an extended process throughout the latter portion of the Late Triassic.

Although now better established by ancestral state reconstructions (Irmis, 2011; Benson et al., 2012, 2014, 2018; Turner and Nesbitt, 2013), tracking the early evolution of large body sizes among Theropoda and Neotheropoda is compounded by the dearth of Triassic specimens. Although apparently cosmopolitan, only three named species of unambiguous larger Triassic neotheropods are known: Zupaysaurus rougieri Arcucci and Coria, 2003 from the Los Colorados Formation of Argentina (PULR 076, a single individual; Ezcurra and Novas, 2007), Liliensternus liliensterni Huene, 1934 from the Trossingen Formation of Germany (HMN MB.R.2175, a two-individual specimen; Welles, 1984; Rauhut and Hungerbühler, 1998), and Gojirasaurus quayi Carpenter, 1997 from the Bull Canyon Formation of New Mexico (UCM 47721, a single individual; Parrish and Carpenter, 1986). Including the 'Bull Canyon Neotheropod' (NMMNH P-4569) and an isolated neotheropod fibula (NMMNH P-4563; Griffin and Nesbitt, in press), worldwide there are only six known individuals of definitive Triassic 
neotheropods larger than typical coelophysoid size ( 200$230 \mathrm{~mm}$ femoral length, $\sim 10 \mathrm{~kg}$ ). The majority of these individuals are incomplete and their phylogenetic position relative to other theropods is poorly constrained among early Neotheropoda, with different analyses variously finding these taxa as more closely related to Coelophysis bauri Cope, 1887 (Carrano et al., 2005; Tykoski, 2005; Yates, 2005; Ezcurra and Cuny, 2007; Ezcurra and Novas, 2007; You et al., 2014) or Averostra (Yates, 2005; Nesbitt et al., 2009; Sues et al., 2011) or in a polytomy at the base of Neotheropoda (Carrano et al., 2005; Ezcurra and Brusatte, 2011; Nesbitt and Ezcurra, 2015). Because of this lack of information, detailed anatomical description of even fragmentary remains of large Triassic neotheropods is valuable to understanding the relationships and evolution of large body size among early theropods and the effect of the end-Triassic mass extinction on this evolutionary trend. In this study, I describe the two fragmentary neotheropod individuals (NMMNH P-4563, P-4569) from the Bull Canyon Formation of New Mexico, as well as the previously undescribed metatarsal V of the Gojirasaurus quayi holotype (UCM 47221), and place these individuals in the context of body size evolution among early Theropoda.

\section{Materials and methods}

Repositories and institutional abbreviations.-FMNH, Field Museum of Natural History, Chicago, Illinois, USA; GR, Ghost Ranch Ruth Hall Museum of Paleontology, Abiquiu, New Mexico, USA; HMN, Museum für Naturkunde, Humboldt Universität, Berlin, Germany; LFGT, Bureau of Land and Resources of Lufeng County, Lufeng, Yunnan, China; MCZ, Museum of Comparative Zoology, Harvard University, Cambridge, Massachusetts, USA; MNA, Museum of Northern Arizona, Flagstaff, Arizona, USA; NHMB, Natural History Museum of Zimbabwe, Bulawayo, Zimbabwe; NMMNH, New Mexico Museum of Natural History and Science, Albuquerque, New Mexico, USA; NMT, National Museum of Tanzania, Dar es Salaam, Tanzania; PULR, Paleontología, Universidad Nacional de La Rioja, La Rioja, Argentina; PEFO, Petrified Forest National Park, Arizona, USA; PVSJ, División de Paleontología de Vertebrados del Museo de Ciencias Naturales y Universidad Nacional de San Juan, San Juan, Argentina; UCM, University of Colorado Museum of Natural History, Boulder, Colorado, USA; UCMP, University of California Museum of Paleontology, Berkeley, California, USA.

\section{Systematic paleontology}

Dinosauria Owen, 1842

Saurischia Seeley, 1887

Theropoda Marsh, 1881

Neotheropoda Bakker, 1986, sensu Sereno et al., 2005

Neotheropoda genus indeterminate species indeterminate Figures 1-10

Diagnosis.-NMMNH P-4569 can be diagnosed as a member of Dracohors (Silesauridae + Dinosauria; Cau, 2018) based on the asymmetrical morphology of the distal end of metatarsal

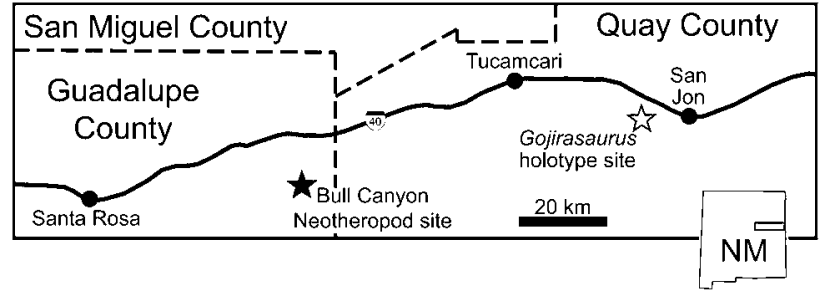

Figure 1. Location of the holotype site of Gojirasaurus quayi and the site from which the Bull Canyon neotheropods (NMMNH P-4563, 4569) were recovered in New Mexico, USA. Redrawn from Hunt (1994, 2001).

IV (Nesbitt, 2011, character 391). Its dinosaurian status is diagnosed by the following characters: concave ventral margin of the acetabulum of the ilium (Nesbitt, 2011, character 273), concave surface of articulation with the fibula of the calcaneum (Nesbitt, 2011, character 378), the proximal articular facet for fibula occupies less than one-third of the transverse width of the element (Nesbitt, 2011, character 362), concave emargination ventral to the femoral head (Nesbitt, 2011, character 304), and calcaneal tuber absent (Nesbitt, 2011, character 373). It can be diagnosed as a member of the clade Tawa + Neotheropoda by an anteromedial tuber of the femur that is offset medially (or posteriorly) relative to the posteromedial tuber (Nesbitt et al., 2009, character 223) and as a neotheropod by astragalocalcaneum co-ossification (Nesbitt et al., 2009, character 283). These character optimizations are largely congruent with those found in other studies (e.g., Ezcurra, 2006; Langer and Benton, 2006; Irmis et al., 2007; Brusatte et al., 2008). NMMNH P-4563 can be diagnosed as a neotheropod by the presence of a ridge on the medial surface of the proximal end of the fibula (Nesbitt et al., 2009, character 314). The Gojirasaurus quayi holotype (UCM 47221), NMMNH P-4569, and NMMNH P-4563 were recovered from geographically close sites in the Bull Canyon Formation (Hunt, 1994; Fig. 1).

Occurrence.-NMMNH Locality 110, Bull Canyon, Quay County, New Mexico (Hunt, 2001; Fig. 1). Bull Canyon Formation (= Cooper Canyon Formation), Late Triassic, Norian (Molina-Garza et al., 1993); Revueltian Faunachron (Lucas and Hunt, 1993; sensu Lucas, 1998; = Revueltian Biozone sensu Parker and Martz, 2010).

Materials.-NMMNH P-4569, disarticulated and partial trunk and caudal vertebrae, partial left scapula, partial manual elements including manual unguals, partial right ilium consisting of pubic peduncle and supraacetabular crest, partial proximal portion of left ischium, proximal end of left femur, partial distal end of left tibia, distal end of left fibula, lateral portion of left astragalocalcaneum, pedal elements including the distal end of left metatarsal IV, the posterodistal portion of right metatarsal II, and pedal phalanges. NMMNH P-4563, proximal portion of left fibula.

Remarks.-Assessment of skeletal maturity: NMMNH P-4569 lacks co-ossification between the scapula and coracoid, pubis and ilium, pubis and ischium, ilium and ischium, tibia and astragalus, tibia and fibula, fibula and calcaneum, possesses 


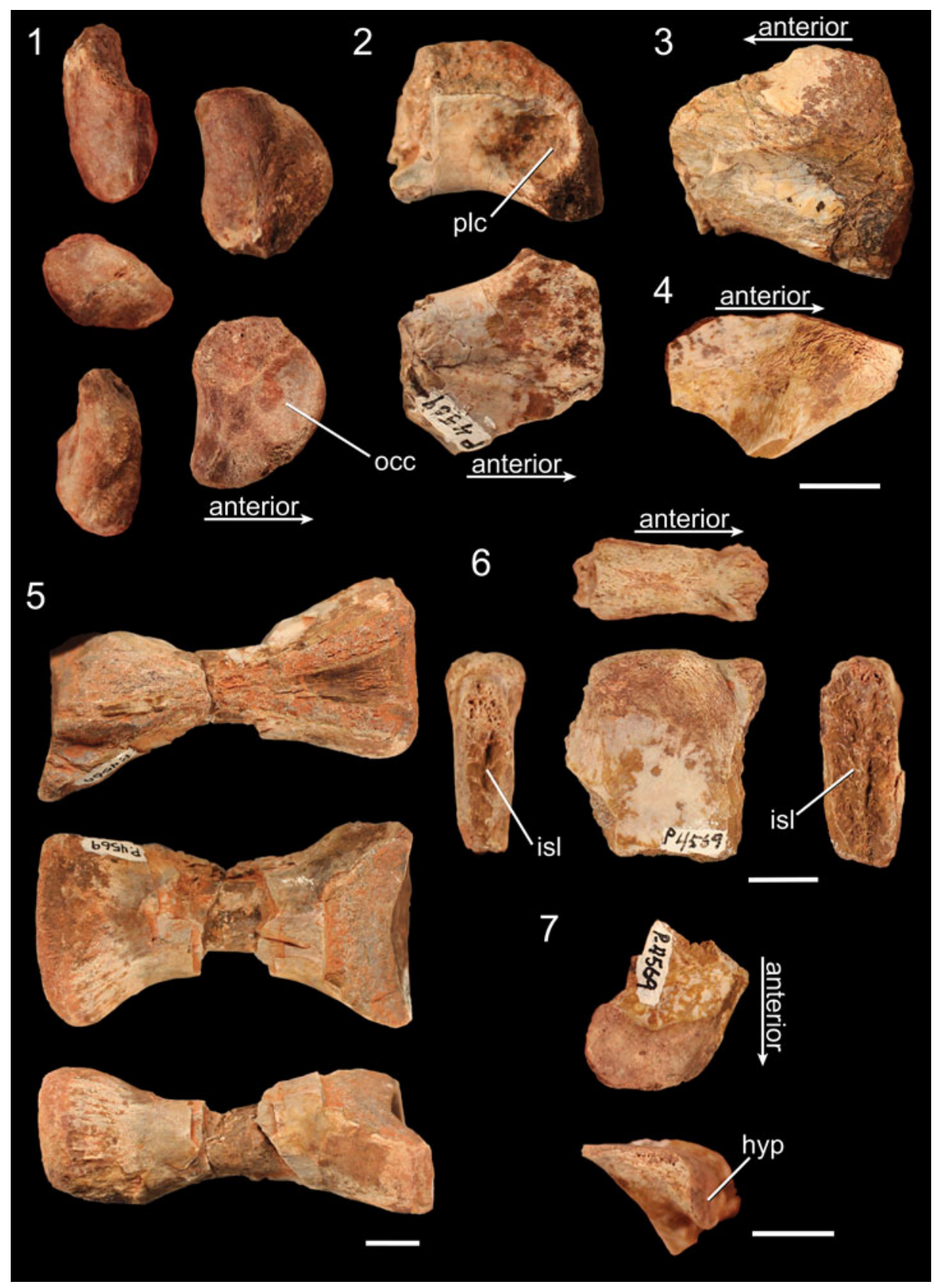

Figure 2. Presacral vertebrae of NMMNH P-4569. (1) Atlantal intercentrum in posterodorsal (top left), right lateral (middle left), anteroventral (bottom left), posteroventral (top right), and anterodorsal (bottom right) views. (2) Fragment of the anterior end of a cervical vertebra in right lateral (top) and ventral (bottom) views. (3) Fragment of the posterior end of a cervical vertebra in left lateral view. (4) Fragment of an epipophysis in dorsal view. (5) Centrum of a trunk vertebra in dorsal (top), lateral (middle), and ventral (bottom) views. (6) Dorsal portion of a neural spine in dorsal (top), posterior (left), right lateral (middle), and anterior (right) views. (7) Fragment of a right prezygapophysis of a trunk vertebra in dorsal (top) and anterior (bottom) views. hyp = hypantrum; isl = surface of connection for interspinous ligaments; occ = surface for articulation with the occipital condyle; plc = pleurocoel. Scale bars $=1 \mathrm{~cm} ;(\mathbf{1 - 4})$ the scale bar is bottom right of 4 .

an astragalocalcaneum that is only partially co-ossified, an open neurocentral suture of a posterior trunk vertebra, and a groove on the proximal surface of the femur; these are all character states that are suggestive of skeletal immaturity in early-diverging neotheropods (Griffin and Nesbitt, 2016, in press; Griffin, 2018). In addition, the osteohistology of rib fragments of this individual suggest that it was not slowing growth at time of death (Griffin and Nesbitt, in press). NMMNH P-4563 possesses a ridge on the medial surface of the proximal end of the fibula, which appears during ontogeny (Rowe and Gauthier, 1990; Griffin, 2018); however, osteohistology of this element suggests that this individual was still growing rapidly at time of death (Griffin and Nesbitt, in press). I therefore interpret these specimens to represent skeletally immature individuals.

\section{Gojirasaurus Carpenter, 1997}

Type species.-Gojirasaurus quayi Carpenter, 1997 from the Bull Canyon Formation of New Mexico, by monotypy. 


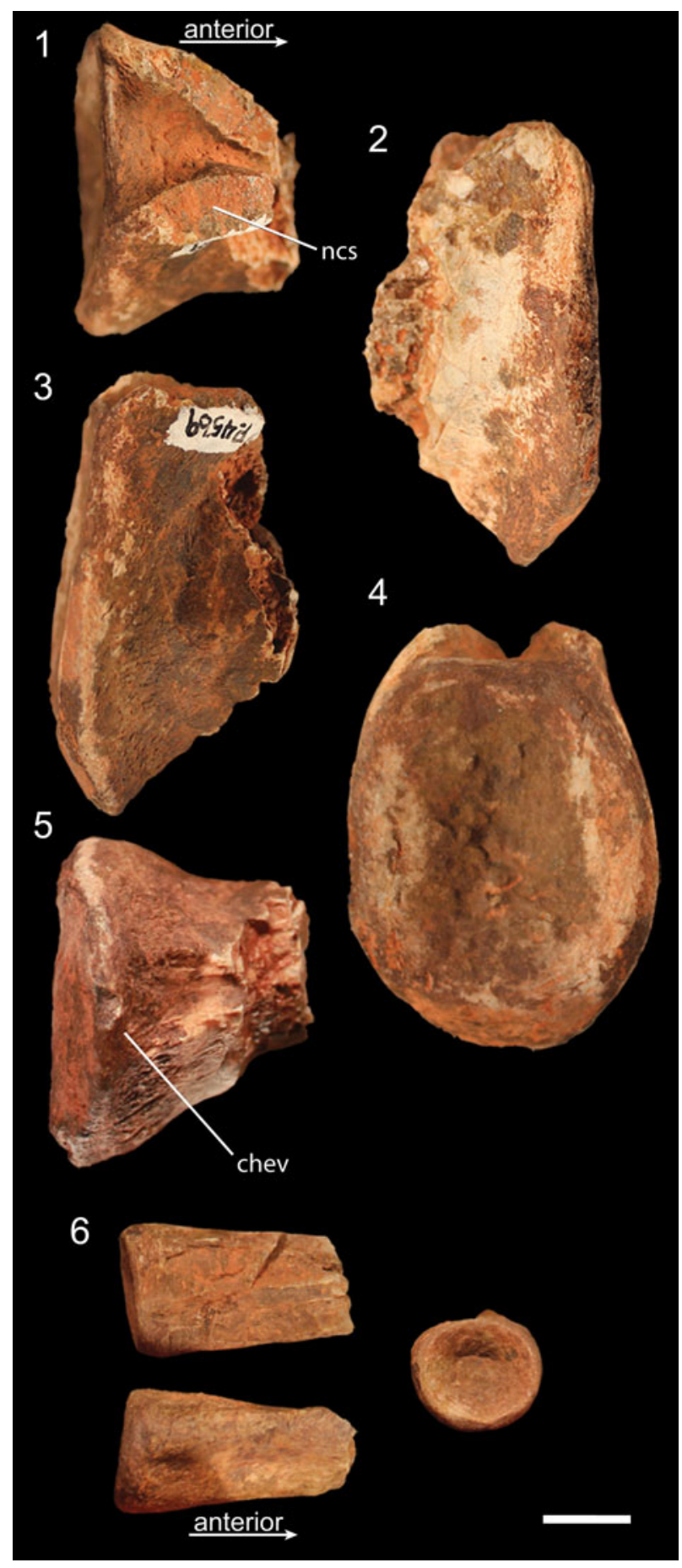

Figure 3. Caudal vertebrae of NMMNH P-4569. (1-5) Posterior portion of proximal caudal vertebra in (1) dorsal, (2) left lateral, (3) right lateral, (4) posterior, and (5) ventral views. (6) Posterior portion of distal caudal in dorsal (top left), ventral (bottom left), and posterior (right) views. chev $=$ articulation surface for chevrons; $\mathrm{ncs}=$ surface of neurocentral suture. Scale bar $=1 \mathrm{~cm}$.

\section{Gojirasaurus quayi Carpenter, 1997}

Figure 11

Holotype.-UCM 47221, tooth, cervical rib, two anterior dorsal ribs, one posterior dorsal rib, four trunk centra, one trunk neural arch, one anterior chevron, two gastralia (?), left scapula, right pubis, left tibia (Carpenter, 1997), and left metatarsal V, which was never described or figured by Carpenter (1997).

Diagnosis. - Nesbitt et al. (2007) diagnosed Gojirasaurus quayi as a nontetanuran theropod and a member of Coelophysoidea based on characters of the pubis (following Rauhut, 2003) and tibia and distinguished it from Coelophysis bauri by its tibia, which is proportionally thicker than that of $C$. bauri. Gojirasaurus quayi is distinguishable from Megapnosaurus rhodesiensis (Raath, 1969; gen. Ivie et al., 2001) by the presence of a raised scar on the anterior surface of metatarsal $\mathrm{V}$ and the absence of a sulcus on the proximomedial surface of metatarsal V. Gojirasaurus quayi is distinguishable from Dilophosaurus wetherilli Welles, 1954 by the nonconvex surface between lateral and anteromedial tubera of metatarsal $\mathrm{V}$ in proximal view.

Occurrence.-UCM locality 82021, Revuelto Creek, Quay County, New Mexico (Carpenter, 1997; Fig. 1). Bull Canyon Formation (= Cooper Canyon Formation), Late Triassic, Norian (Molina-Garza et al., 1993); Revueltian faunachron (Lucas and Hunt, 1993; sensu Lucas, 1998; = Revueltian Biozone sensu Parker and Martz, 2010).

\section{Materials.-UCM 47221 (holotype) metatarsal V.}

Remarks.-Assessment of skeletal maturity: this individual lacks co-ossification between sacral vertebrae, scapula and coracoid, pubis and ilium, pubis and ischium, tibia and astragalus, tibia and fibula, possesses open neurocentral sutures of sacral and trunk vertebra, lacks a tuberosity on the anterior and anteromedial portion of the cnemial crest, and lacks a scar on the posterior portion of the medial surface of the proximal end of the tibia; these are all character states that are suggestive of skeletal immaturity in early-diverging theropods (Griffin and Nesbitt, 2016, in press; Griffin, 2018). I interpret this specimen to represent a skeletally immature individual.

\section{Description}

Cervical vertebrae of NMMNH P-4569.-The only portion of the atlas-axis complex of NMMNH P-4569 is the atlantal intercentrum, which is largely complete but is missing part of the dorsal portion of the left side. This element is semicircular in dorsal view, with a depression for articulation with the occipital condyle on the anterior portion of the anterodorsal surface. In NMMNH P-4569, this articular surface is roughly circular and is narrower mediolaterally, with the anteriormost portion of the articular surface convex in dorsal view (Fig. 2.1) unlike the atlantal intercentrum of Herrerasaurus ischigualastensis Reig, 1963 (Sereno and Novas, 1994, fig. 11) and Dilophosaurus wetherilli (UCMP 37302), in which the surface for articulation with the occipital condyle is rectangular and as mediolaterally wide as the posterior portion of the intercentrum body. A raised portion posterior to the articular surface for the occipital condyle separates this surface from the articular surface for the odontoid process, which is proportionally smaller. A slight depression on the right 

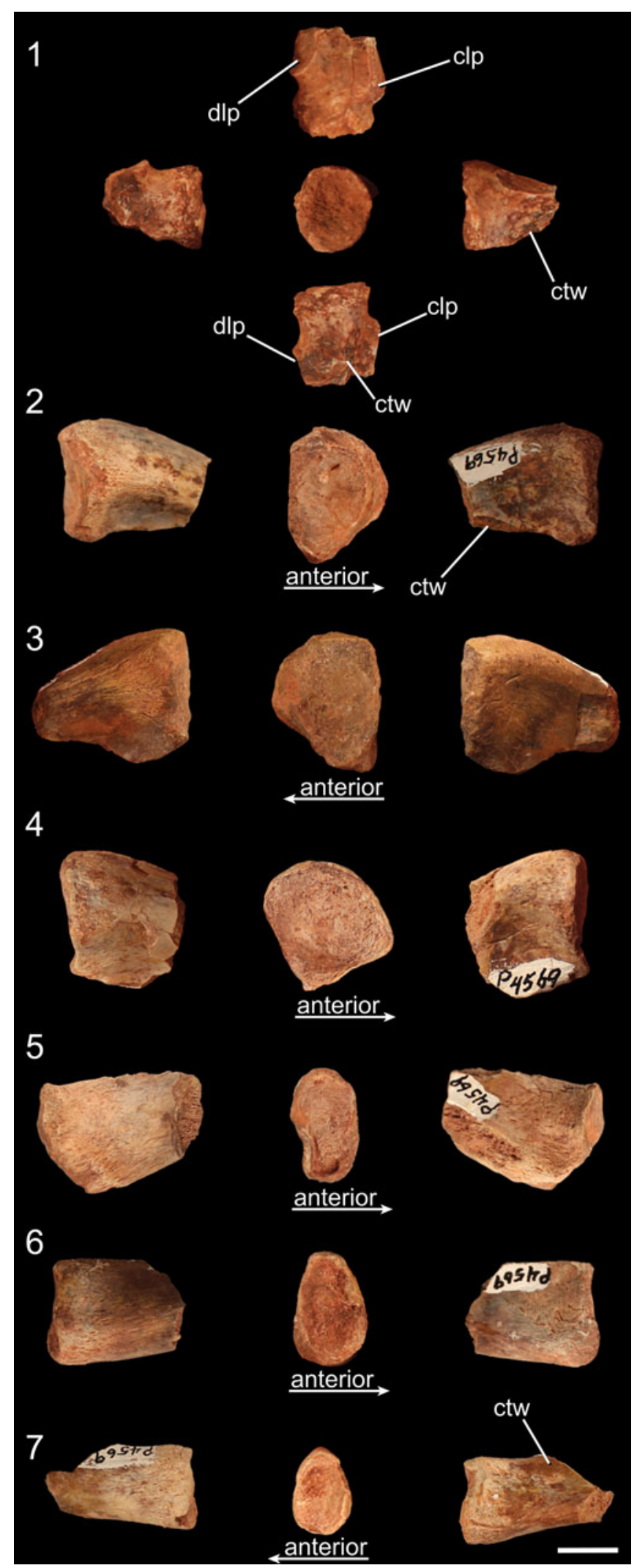

Figure 4. Rib fragments of NMMNH P-4569. (1) Left cervical tuberculum in dorsal (top), medial (middle), ventral (bottom), posterior (left), and anterior (right) views. (2-4) Trunk tubercula in anterior (left), medial (middle), and posterior (right) views; $(\mathbf{2}, \mathbf{4})$ left ribs; $(\mathbf{3})$ a right rib. (5-7) Trunk capitula in anterior (left), medial (middle), and posterior (right) views; $(\mathbf{5 , 6})$ left ribs; (7) a right rib. $\mathrm{clp}=$ connection to the craniolateral process; $\mathrm{ctw}=$ capitulotuberculum web; $\mathrm{dlp}=$ connection to the dorsolateral process. Scale $\mathrm{bar}=1 \mathrm{~cm}$. portion of the dorsal surface further separates these two articular surfaces (Fig. 2.1). The anterior half of the ventral surface of the atlantal intercentrum possesses a rugose texture, whereas the posterior half that articulates with the axial intercentrum is smooth; a rugose ridge separates these two halves. There are depressions on the right and left sides of the anterior half of the ventral surface so that the medial portion of the ventral surface is raised relative to the right and left sides.

A fragment of the dorsal portion of the anterior part of a right cervical centrum possesses a rimmed fossa (Fig. 2.2), similar to those of Liliensternus liliensterni (HMN MB.R.2175) and Coelophysis bauri (e.g., AMNH FARB 7224) and previously interpreted as the anterior pleuroceol (e.g., Holtz, 1994; Rauhut, 2003; Smith et al., 2007). Tawa hallae Nesbitt et al., 2009, as well as coelophysoids (e.g., C. bauri, Megapnosaurus, Panguraptor You et al., 2014), possesses the anterior cervical pleurocoels as fossae, whereas in the majority of noncoelophysoid neotheropods (including Dilophosaurus) these pleurocoels are in the form of a foramen or foramina (Rauhut, 2003; Nesbitt et al., 2009; Nesbitt and Ezcurra, 2015). There are two subtle paramedian ridges on the ventral surface of this cervical centrum separated by a shallow depression (Fig. 2.2). A partial cervical vertebra that preserves the posterior portion of the centrum shows that NMMNH P-4569 possesses a rimmed posterior depression (Fig. 2.3) similar to those of the cervical vertebrae of Dilophosaurus wetherelli (UCMP 77270), although the rim is not as sharp as in D. wetherelli. The posterior articular surface of the centrum is deeply concave. There is one partial left epipophysis of an anterior cervical vertebra (Fig. 2.4), which is a synapomorphy of Dinosauria (Langer and Benton, 2006; Nesbitt, 2011) and is a synapomorphy of Aphanosauria, the earliest-diverging lineage of bird-line archosaurs (Nesbitt et al., 2017).

Trunk vertebrae of NMMNH P-4569.-There are 15 larger fragments of vertebral centra in NMMNH P-4569 along with many smaller fragments of centra, and only a few can be confidently identified as belonging to the centra of trunk or caudal vertebrae. All but one of the centra are, at most, preserved as anterior or posterior halves, with a single trunk centrum that retains its entire anteroposterior length. In dorsal view, the surface of the neural canal is a smooth anteroposterior depression bordered laterally by the lateral walls of the centrum, which form the junction between the centrum and neural arch. The two ridges that form the neural canal are compressed mediolaterally in the middle of the centrum, forming a ' $\mathrm{V}$ ' shape in dorsal view on the anterior and posterior ends of each centrum. It is impossible to determine whether the neurocentral sutures of the trunk vertebrae are partially or fully fused: the dorsal surfaces of the ridges that form the articulation between the centrum and neural arch are missing, as evidenced by the cancellous bone visible between the medial and lateral surfaces of each ridge. All centra are amphicoelous and hourglass shaped (or would have been, if complete) in lateral and dorsal view, with a fossa on the lateral side of the centrum body.

The articular surfaces of the trunk vertebrae are circular in anterior or posterior view, respectively, and this is most clearly seen in the most complete centrum (Fig. 2.5). This centrum 


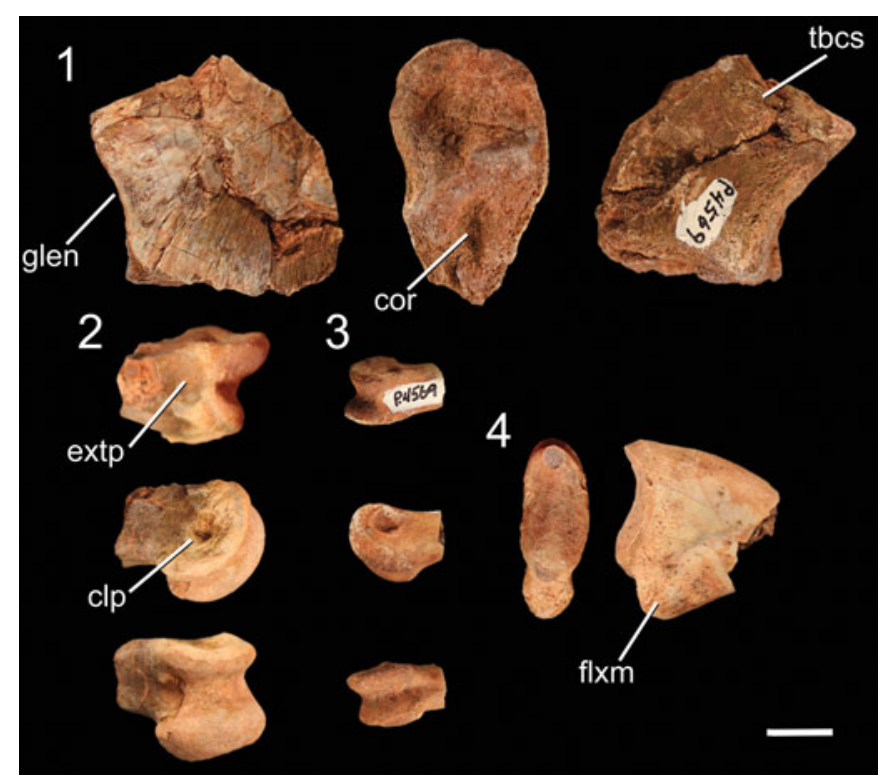

Figure 5. Pectoral girdle and forelimb elements of NMMNH P-4569. (1) Fragment of the proximal end of the left scapula in medial (left), distal (middle), and lateral (right) views. (2) Distal end of a larger manual phalanx in dorsal (top), lateral (middle), and ventral (bottom) views. (3) Distal end of a smaller manual phalanx in dorsal (top), lateral (middle), and ventral (bottom) views. (4) Manual ungual in proximal (right) and lateral (left) views. clp $=$ collateral ligament pit; cor = surface for articulation with the coracoid; extp = extensor pit; flxm = mound for insertion of flexor ligaments (= flexor tubercle); glen = glenoid; tbcs $=$ scar for the origin of the triceps brachii caput scapulare. Scale bar $=1 \mathrm{~cm}$.

(and other less complete trunk centra) possesses subtle anteroposteriorly oriented ridges, roughly $5-10 \mathrm{~mm}$ in length, just anterior or posterior, respectively, to the articular surfaces. No parapophyses or diapophyses are preserved except for two partial diapophyses (a left and a right) of trunk vertebrae. These diapophyses are missing most of their anterior and posterior portions, but the lateralmost portion is preserved in both elements, along with the lateralmost portion of the diapophyseal lamina (sensu Wilson, 1999). Both diapophyses are anteroposteriorly elongate, roughly 4 times anteroposteriorly wide than dorsoventrally tall in lateral view. Two isolated right prezygapophyses possessing the right lateral side of the hypantrum are preserved from this individual (Fig. 2.7), and because this accessory articulation is present in the trunk vertebrae of early theropods (e.g., Gauthier, 1986; Rauhut, 2003; Langer and Benton, 2006; Nesbitt, 2011), these prezygapophyses are likely from this portion of the vertebral column.

There is an isolated neural spine, but there is not enough information preserved to identify it as belonging to a trunk, sacral, or caudal vertebra. Although only the dorsal portion of the neural spine is preserved (Fig. 2.6), it is still dorsoventrally taller than anteroposteriorly wide, and the anterior surface of the spine is mediolaterally wider than either the posterior surface or the medial portion of the spine. Both the anterior and posterior surfaces of the spine are roughened, which in extant archosaurs is scarring from the attachment of interspinous ligaments (Tsuihiji, 2004; Woodruff, 2014; Wilson et al., 2016), and these scars extend to the dorsal margin of the neural spine. The anterior surface of the neural spine is straight in lateral view, whereas the posterior surface is angled in lateral view. A bulbous tuber, which in extant birds (e.g., Rhea americana Linnaeus, 1758; Tsuihiji, 2004) represents an attachment point for muscles, extends over the posterior three-fourths of the distal end of the neural spine and is mediolaterally widest at its posterior end (Fig. 2.6).

Caudal vertebrae of NMMNH P-4569.-The single proximal caudal vertebra centrum of NMMNH P-4569 consists of the posterior end, possessing an oval-shaped articular surface roughly 1.25 times dorsoventrally taller than mediolaterally wide. The posteriormost portion of the ventral surface of this centrum possesses a double ridge, presumably for articulation with the chevrons. These two narrow ridges are approximately $1 \mathrm{~cm}$ apart, with a shallow trough between them; the two ridges converge anteriorly but do not intersect on the portion that is preserved. The ventral portion of the centrum articular surface is angled anteroventrally in lateral view (Fig. 3.2, 3.3). This is the only element to preserve an intact dorsal surface of the lateral surface of the centrum, indicating that the neurocentral suture was not fused to the centrum in this vertebra.

NMMNH P-4569 also possesses the posterior end of a distal caudal centrum. This centrum is extremely anteroposteriorly elongate (assuming it is broken in half, it is over three times anteroposteriorly long as mediolaterally wide), and the posterior articular surface is circular. The posterior end of the ventral surface possesses a low double ridge presumably for articulation with the chevrons (Fig. 3.6), and there are subtle depressions on the lateral sides of the posterior end of the centrum in lateral view.

Ribs of NMMNH P-4569.-There are 10 fragments of the proximal portions of ribs in NMMNH P-4569: one tuberculum of a left cervical rib, four tubercula of trunk ribs, and five capitula of trunk ribs. The tuberculum of the left cervical rib possesses a subcircular articular surface for the diapophysis, and the laminae connecting the tuberculum to the dorsolateral process and the craniolateral process (sensu O'Connor, 2007), as well as the capitulotubercular web, are broken but distinguishable (Fig. 4.1).

The articular surfaces of the tubercula of the trunk ribs are subtriangular (Fig. 4.2-4.4). The proximalmost portion of the anterior cranial intercostal ridge (sensu O'Connor, 2007) is present on the anterior surface of all tubercula, and on the posterior side of each is a subtle depression between the lateral edge of the rib and the beginning of the capitulotubercular web (sensu O'Connor, 2007). The tubercula vary in the relative anteroposterior widths of their articular surfaces, so that some are more anteroposteriorly narrow than others.

The five trunk capitula possess roughly elliptical, rimmed articular surfaces (Fig. 4.5-4.7). The ventral surfaces of the shaft of the capitula are rounded, whereas the dorsal surfaces are anteroposteriorly compressed, forming a ridge that in turn forms the medioventral portion of the capitulotubercular web. Whereas the anterior surfaces of the shafts of the capitula are convex, the posterior surfaces are concave.

Scapula of NMMNH P-4569. - The pectoral girdle of NMMNH P-4569 is represented by a fragment of the proximal end of the left scapula, which consists of only the scapular section of the glenoid fossa and part of the articulation with the coracoid. The scapula 


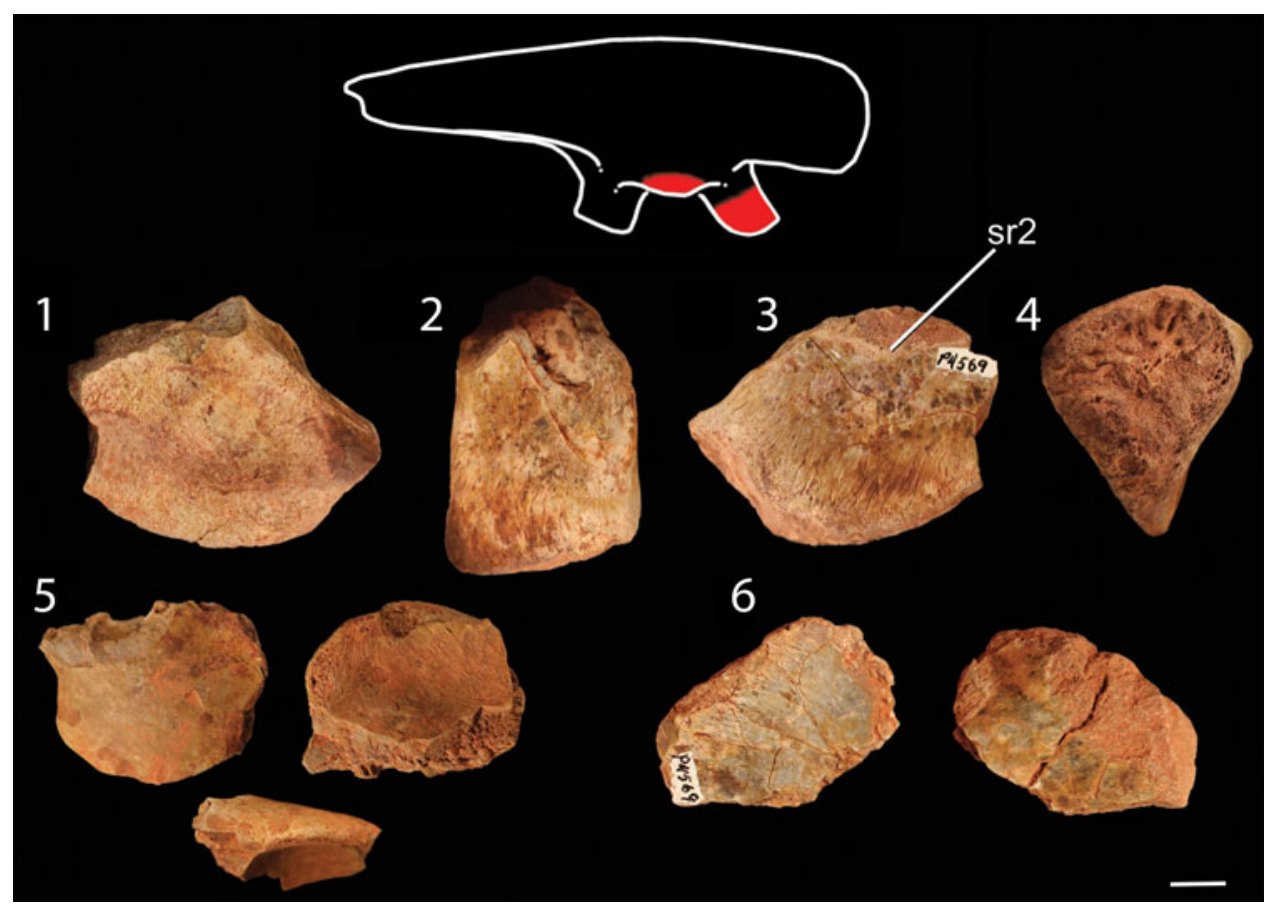

Figure 6. Pelvic girdle elements of NMMNH P-4569, with outline of an idealized right ilium in lateral view showing the location of the iliac fragments of NMMNH P-4569 in red. (1-4) Pubic peduncle of right ilium in (1) lateral, (2) anterodorsal, (3) medial, and (4) anteroventral views. (5) Right supraacetabular crest in dorsal (top left), ventral (top right), and posterior (bottom) views. (6) Fragment of left ischium in lateral (left) and medial (right) views. sr2 = surface for articulation with sacral rib 2. Scale bar $=1 \mathrm{~cm}$.

and coracoid are not co-ossified. The scapular section of the glenoid fossa is rounded in posterior view, with a slight depression that is more developed in the medial portion of the surface of the glenoid fossa than in the lateral portion. The scapula is mediolaterally thickest at the glenoid fossa (Fig. 5.1) and narrows anteriorly from this surface and along the articulation surface with the coracoid. The medial portion of this section of the scapula is slightly convex, and the lateral surface is slightly concave. The medial surface possesses thin linear grooves, morphologically similar to the lineations present on some elements of the pelvic girdle (see below), oriented proximodistally at roughly right angles to the articular surfaces. A small raised, rugose scar interpreted as the origin of the triceps brachii caput scapulare (Burch, 2014) is present just posterodorsal to the edge of the glenoid fossa (Fig. 5.1).

Manus of NMMNH P-4569.-The only elements preserved of NMMNH P-4569 that can be confidently identified as manual are a few partial distal phalanges and a partial ungual (Fig. 5.2, 5.3). These phalanges can be identified as manual elements by their small size and proportionally narrow mediolateral width relative to other phalanges I interpret as pedal (see below). The distal ends of these distal phalanges possess two well-developed condyles with deep ligament pits on the medial and lateral surfaces, and each has a well-developed extensor pit on its dorsal surface. Grooves separating the condyles extend from the ventral surface around the distal surface of the phalanx (clearly defining the condyles) to the dorsal surfaces. Both condyles of these phalanges possess notches on their ventral surfaces, but in the larger phalanx these notches are much more distinct. In addition, both condyles extend dorsally above the shaft of the phalanx in both phalanges, and both phalanges possess asymmetrical condyles: in the larger phalanx, the left condyle is mediolaterally thicker and extends further both anteriorly and distally, and in the right phalanx the two condyles are roughly similar in size but the left condyle extends further distally (Fig. 5.2). Comparing the manual elements of NMMNH P-4569 with the manus of Dilophosaurus wetherilli (Welles, 1984, fig. 29), the medial condyles are the largest; this indicates that these phalanges both belong to the right manus.

The manual ungual (Fig. 5.4) is strongly mediolaterally compressed. The articular surface has a vertical ridge in the mediolateral middle separating the medial and lateral cotyli, and the dorsal and ventral portions of the articular surface extend proximally into the dorsal and ventral intercondylar processes, making this surface appear U-shaped in lateral view. There is a large mound, the flexor tubercle, ventral to the articular surface (Fig. 5.4), and a shallow depression separates this process from the rest of the ungual on both the lateral and medial sides. The sides of the ungual possess thin proximodistal grooves near the articular surface and the flexor tubercle.

Ilium of NMMNH P-4569.-The pelvic girdle of NMMNH P-4569 consists of the pubic peduncle of the right ilium, the proximal end of the right ischium, and the supra-acetabular crest of the right ilium (Fig. 6). The pubis is not fused to the ilium, and the pubic facet of the pubic peduncle has a wrinkled, rugose articular surface in proximal view. This articulation is proportionally mediolaterally wider than that 


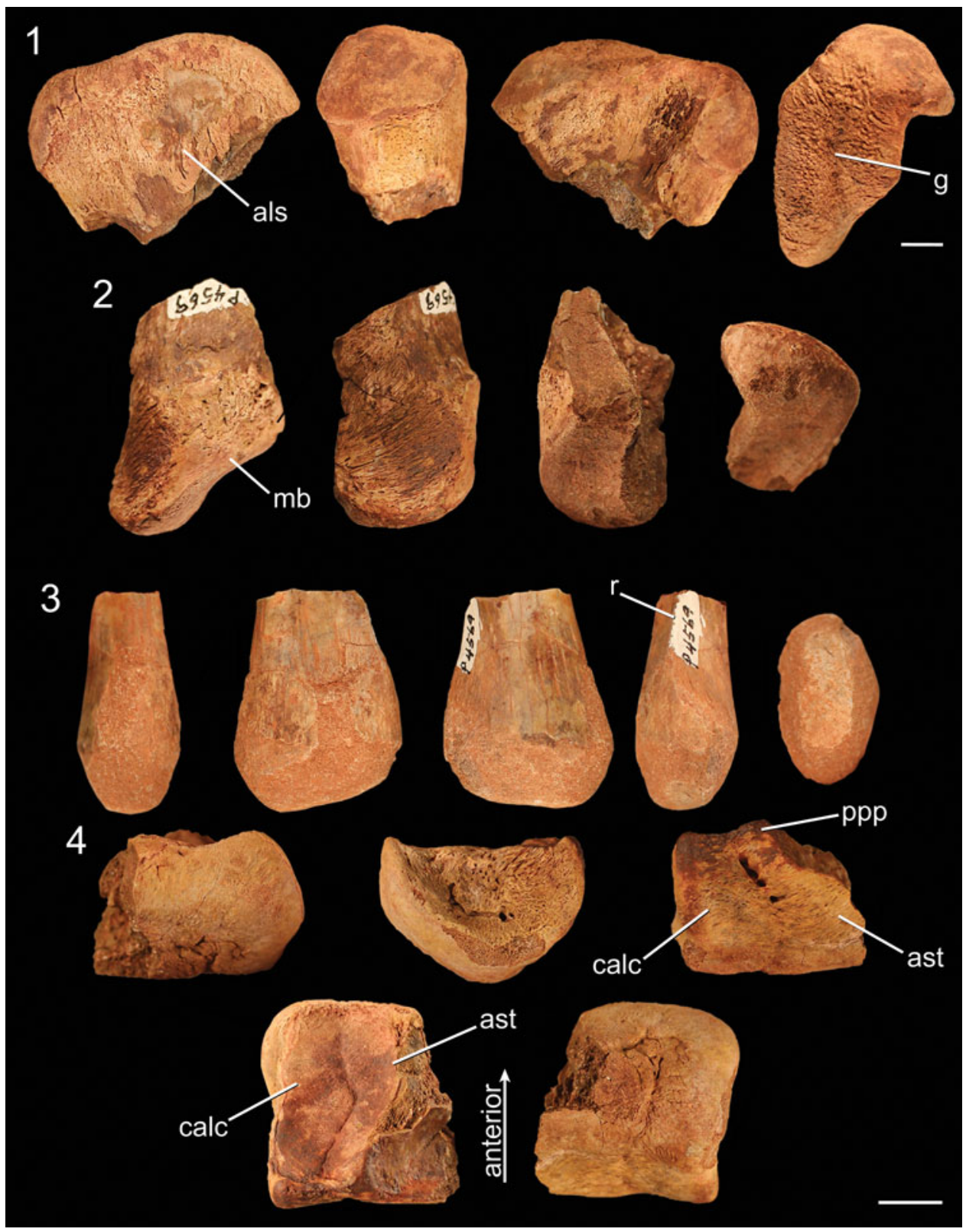

Figure 7. Hindlimb elements of NMMNH P-4569. (1) Proximal end of left femur in anterolateral (far left), anteromedial (middle left), posteromedial (middle right), and proximal (far right) views. (2) Distal end of left tibia in anterior (far left), medial (middle left), lateral (middle right), and distal (far right) views. (3) Distal end of left fibula in posterior (far left), medial (middle left), lateral (middle), anterior (middle right), and distal (far right) views. (4) Lateral fragment of left astragalocalcaneum in anterior (upper left), lateral (upper middle), posterior (upper right), proximal (lower left), and distal (lower right) views. als $=$ anterolateral scar; ast $=$ astragalus; calc $=$ calcaneum; $\mathrm{g}$, groove; $\mathrm{mb}=$ medial buttress; $\mathrm{ppp}=$ posterior pyramidal process; $\mathrm{r}=$ ridge. All scale bars $=1 \mathrm{~cm} ;(\mathbf{1})$ the scale bar is in the far bottom right of this section.

of Coelophysis bauri (Griffin, 2018) and is roughly as mediolaterally wide as it is anteroposteriorly long (Fig. 6.16.4) and triangular in ventral view. A small mound on the posterolateral side of the peduncle is visible in lateral view, and the posterior portion of the peduncle forms the anterior part of the acetabulum. This anterior portion of the acetabulum and the pubic facet form a continuous surface of roughly textured bone similar to that of long bone epiphyses (e.g., the proximal end of the femur, see the following). This texture extends from the ventral surface around to the lateral surface of the anterior edge of the acetabulum, creating a small raised area of rough bone, but it does not extend medially to the medial surface.
The anterodorsal surface of the peduncle is flat with a consistent mediolateral width along the section that is preserved. There is a section missing from the mediodistal area of the anterior surface of the peduncle where the preacetabular (= anterior) process of the ilium would have been present. This break extends to the articular surface for sacral rib 2 (= primordial sacral 1; Nesbitt, 2011), and all but the most proximal portion of this articular surface is missing. The remnant of this surface is visible in medial view and extends posteriorly from the anterior end of the medial surface. The cortical bone on the anterior and medial faces of the pubic peduncle possesses thin proximodistal grooves on the medial 


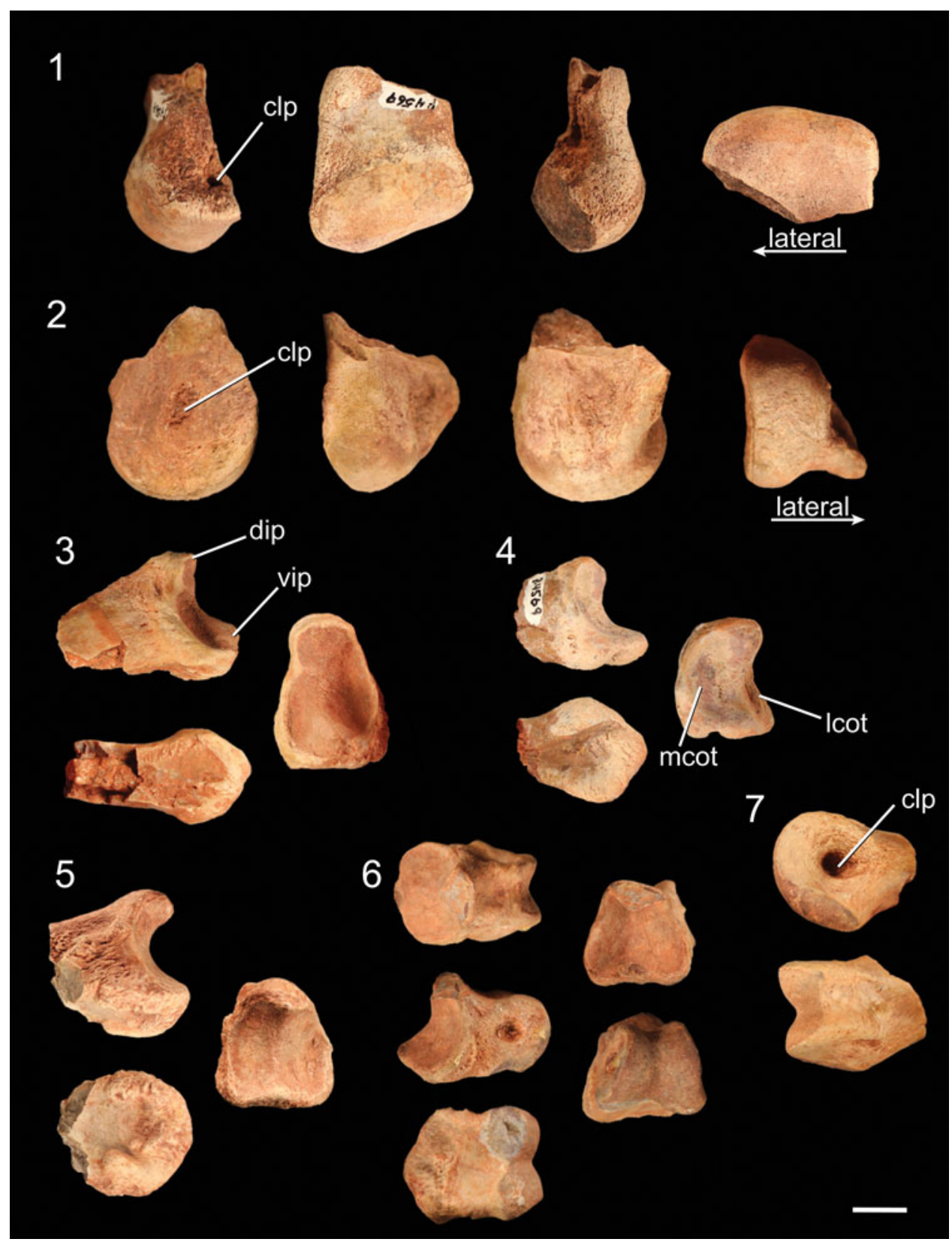

Figure 8. Pedal elements of NMMNH P-4569. (1) The dorsodistal portion of right metatarsal II in medial (far left), anterior (middle left), lateral (middle right), and distal (far right) views. (2) The distal portion of left metatarsal IV in medial (far left), anterior (middle left), lateral (middle right), and distal (far right) views. (3) Proximal pedal phalanx in lateral (top left), ventral (bottom left), and proximal (right) views. (4) Proximal portion of pedal phalanx in lateral (top left), ventral (bottom left), and proximal (right) views. (5) Proximal portion of pedal phalanx in lateral (top left), ventral (bottom left), and proximal (right) views. (6) Distal pedal phalanx in dorsal (top left), lateral (middle left), ventral (bottom left), proximal (top right), and distal (bottom right) views. (7) Distal portion of pedal phalanx in lateral (top) and dorsal (bottom) views. clp = collateral ligament pit; $\mathrm{dip}=$ dorsal intercondylar process; 1 cot $=$ lateral cotylus; mcot $=$ medial cotylus; vip = ventral intercondylar process. Scale bar $=1 \mathrm{~cm}$.

and dorsal surfaces bordering the articular facets. Posteriorly, the peduncle narrows mediolaterally, and the ventral margin of the ilium that forms the acetabulum is narrower mediolaterally than the anterior portion of the peduncle. This ventral margin is concave in lateral view, forming a perforated acetabulum as present in all early dinosaurs (e.g., Gauthier, 1986; Langer and Benton, 2006; Nesbitt, 2011).

The only other fragment of the right ilium preserved is a fragment of the supra-acetabular crest (Fig. 6.5), which is roughly $3 \mathrm{~cm}$ long mediolaterally. The supra-acetabular crest is roughly semicircular in dorsal view, and the ventral surface is concave. In Coelophysis bauri (e.g., AMNH 7223, 7224), the crest joins the rest of the ilium at a higher angle on the posterior end than on the anterior end, and this enables the left-right determination of this specimen, which appears to possess this same anteroposterior asymmetry. The ventral side of the supra-acetabular crest is convex in ventral view, and the ventral surface is composed of rough bone with thin linear ridges. The supra-acetabular crest is dorsoventrally thickest anteriorly and thins posteriorly. 

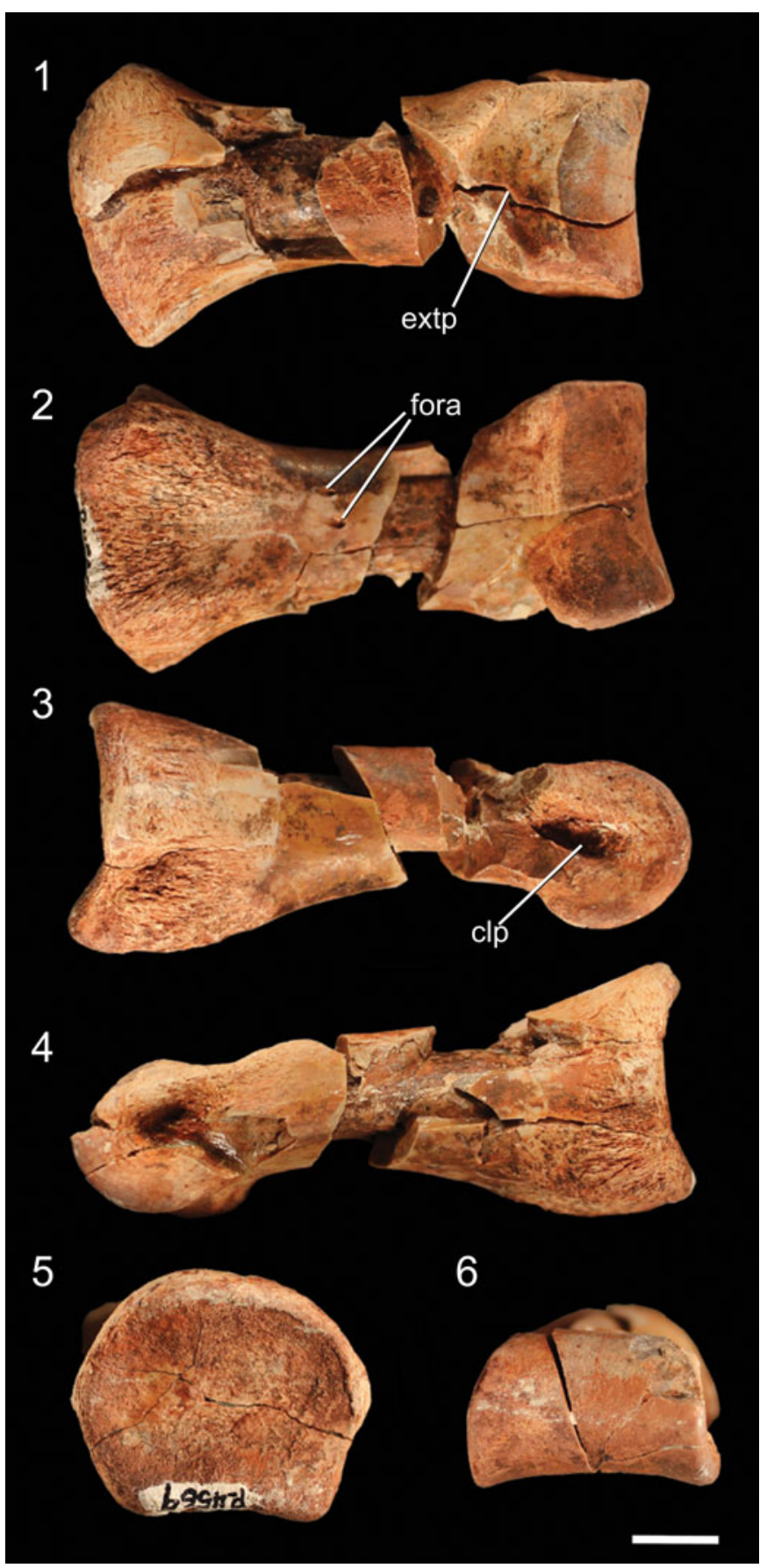

Figure 9. Well-preserved proximal pedal phalanx of NMMNH P-4569 in (1) dorsal, (2) ventral, (3) ?right lateral, (4) ?left lateral, (5) proximal, and (6) distal views. $\mathrm{clp}=$ collateral ligament $\mathrm{pit}$; $\mathrm{ext}=$ extensor $\mathrm{pit}$; fora $=$ foramen. Scale bar $=1 \mathrm{~cm}$

Ischium of NMMNH P-4569.-Only a small portion of the ischial articulation surface of the right ischium of NMMNH P-4569 is preserved (Fig. 6.6), and this articulation surface has a similar texture to that of the articulation surface of the pubic peduncle of the ilium. The ischial facet is damaged but appears to have similar texture as well, suggesting that the pubis was unfused to both the ilium and ischium. The medial surface of the ischium has proximodistally oriented parallel grooves similar to those on the medial surface of the pubic peduncle of the ilium, and the medial surface of the ischium is flat. The lateral surface of the ischium is more rounded, but the damage on this side obscures whether similar proximodistal lineations are present on this side.

Femur of NMMNH P-4569.-Only the proximal portion of the left femur is present in NMMNH P-4569. The width of the proximal end of the femur, from the anteromedial surface of the head to the posterolateral surface of the lateral margin is $65.41 \mathrm{~mm}$, making it roughly $260 \%$ the size of the largest Coelophysis bauri specimens (Griffin, 2018). In proximal view, the anterolateral tuber is well defined and extends anterolaterally. The posteromedial tuber has a size and morphology similar to the anterolateral tuber, and in proximal view the two are separated by a shallow linear groove that extends from just posterolateral to the posteromedial tuber to directly between these tubera on the articular surface of the femur (Fig. 6.1). The anteromedial tuber is offset medially from the femoral head and appears 'hooked' posteromedially in proximal view as in other dinosaurs (e.g., Langer and Benton, 2006; Nesbitt et al., 2009; Nesbitt, 2011). The medial and anteromedial articular surface of the anteromedial tuber has a rugose texture similar to that of the articular surfaces of the pubis and ischium. The femoral head is bordered ventrally by a concavity along the distal edge of the anteromedial tuber (Fig. 6.1). The rough articular surface is confined to the proximal surface for all areas but the anteromedial surface, where it extends distally to cover half of the femoral head and anteromedial tuber. Most of the anterolateral surface of the proximal end of the femur is porous, with many lineations and indentations with no visible preferred orientation. However, just lateral to the anterolateral tuber on the anterolateral surface of the femur, an area of smoother compact bone $\sim 1.5 \mathrm{~cm}$ in diameter interrupts this texture. This smooth region of compact bone on the anterolateral surface of the femur does not appear to be continuous with the porous bone; rather, the smooth bone underlies the porous bone. This area of smooth bone is bordered distally by a ridge of thick $(\sim 1 \mathrm{~mm})$ porous bone, forming the anterolateral scar that is also present in many early neotheropods, including Coelophysis bauri and Megapnosaurus rhodesiensis (Griffin, 2018). The porous texture is present on the posterodistal surface of the femur as well, though it is not as extensive on the areas directly lateral to the anteromedial tuber and distolateral to the posteromedial tuber. The posterolateral portion of the proximal surface of the femur is depressed, forming a smooth transition between the proximal and the posterolateral surfaces of the femur. The locations of the dorsolateral and anterior trochanters, the trochanteric shelf, the obturator ridge, and all other bone scars are not preserved. Given the small portion of the femur that is available, this element is largely indistinguishable from other early-diverging neotheropods (e.g., Dilophosaurus wetherilli Welles, 1984; Cryolophosaurus ellioti Hammer and Hickerson, 1994; Smith et al., 2007; Coelophysis bauri, Megapnosaurus rhodesiensis Griffin, 2018).

Tibia of NMMNH P-4569.-The only section of the tibiae of NMMNH P-4569 present is a partial anteromedial portion of 


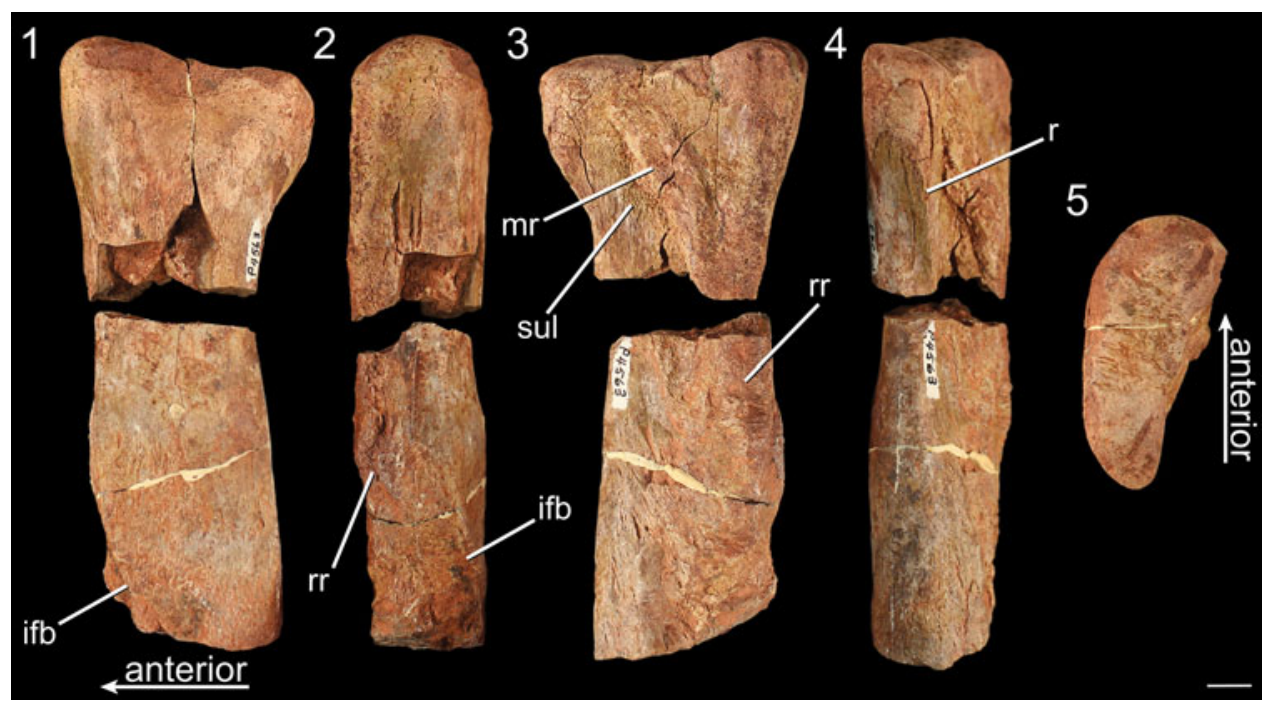

Figure 10. The proximal end of the left fibula of NMMNH P-4563 in (1) lateral, (2) anterior, (3) medial, (4) posterior, and (5) proximal views. ifb =iliofibularis tubercle; $\mathrm{mr}=$ medial ridge; $\mathrm{r}=$ ridge; $\mathrm{rr}=$ rugose ridge; sul $=$ sulcus. $\mathrm{Scale}$ bar $=1 \mathrm{~cm}$.

the distal end of the left tibia. This flange extends roughly $1.5 \mathrm{~cm}$ distally from the surface for articulation with the anterior ascending process of the astragalus, and much of the posterior portion is missing. The medial surface of this flange is rough and proximodistally straight in anterior view. The anterior surface of articulation with the astragalus (= medial buttress of Smith et al., 2007) is similar in texture to other long bone epiphyses (e.g., the femur), but this texture does not extend to the distal surface. The anterior surface possesses a rough texture from the border of the articular surface to roughly $1.5 \mathrm{~cm}$ proximal to this border on the surface of the bone, where it abruptly transitions to a smoother bone texture. A small mound on the anteromedial surface of this portion marks this transition. This tibia is therefore nearly identical to those of Gojirasaurus quayi (Carpenter, 1997) and smallbodied coelophysoids (Ezcurra and Brusatte, 2011; Nesbitt

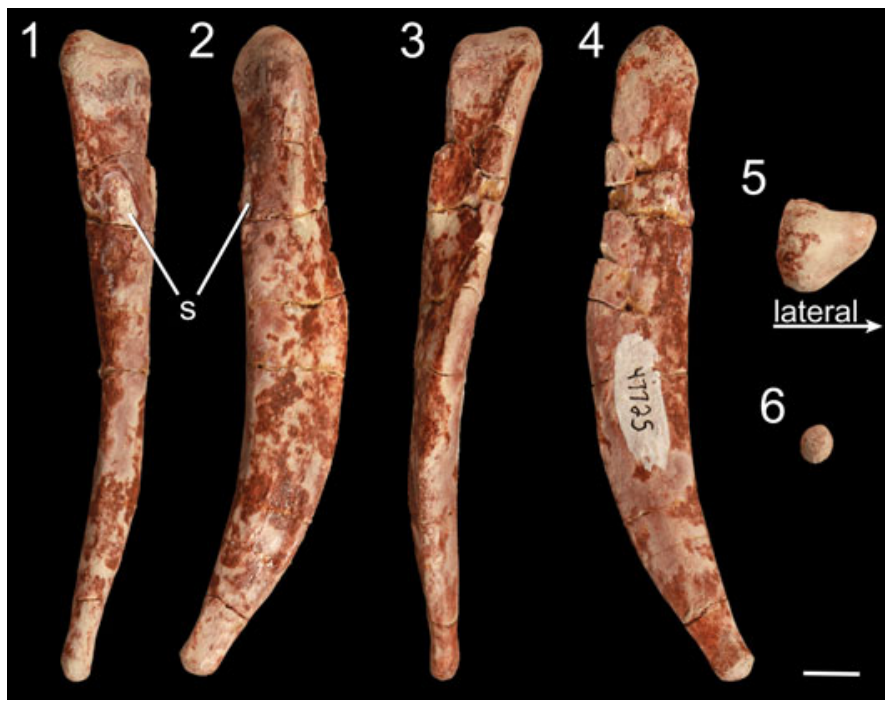

Figure 11. Right metatarsal V of Gojirasaurus quayi (UCM 47221) in (1) anterior, (2) lateral, (3) posterior, (4) medial, (5) proximal, and (6) distal views. $\mathrm{s}=$ scar. Scale bar $=1 \mathrm{~cm}$. and Ezcurra, 2015), but most of the tibial regions that might distinguish it from other early neotheropod taxa are missing (Fig. 7.2). The medial buttress for articulation with the ascending process of the astragalus is more expanded proximally than the medial buttresses of either Eodromaeus murphi Martinez et al., 2011 (PVSJ 562) or Tawa hallae (GR 242; unnumbered GR specimens), and in this respect is more similar to the tibiae of other neotheropods.

Fibula of NMMNH P-4569.- - The distal portion of the left fibula of NMMNH P-4569 is rounded and weathered, but the distal surface of the epiphysis is still preserved, allowing the general morphology of the end of the fibula to be discerned (Fig. 7.3). The distal end of the fibula dips posteriorly in lateral view, so that the posterior portion of the epiphysis is slightly distal to the anterior portion, as in early neotheropods as well as Eodromaeus murphi (PVSJ 562), Tawa hallae (GR 242), and Herrerasaurus ischigualastensis (PVSJ 407). The distal portion of the shaft that is present is longer anteroposteriorly than mediolaterally, and the posterior portion of the shaft is rounded. By contrast, the anterior portion of the shaft is compressed mediolaterally, creating a ridge on the anteromedial portion of the fibula similar to the condition in coelophysoids (Ezcurra and Brusatte, 2011; Nesbitt and Ezcurra, 2015) and Dilophosaurus wetherilli (Welles, 1984) but unlike Tawa hallae (e.g., GR 242), in which the distal end of the fibular shaft is round anteriorly and posteriorly. The medial surface of the shaft, immediately medial to this anterior ridge, is shallowly concave, though this sulcus does not extend distally as far as that of the fibula of Eodromaeus murphi (PVSJ 562).

Tarsus of NMMNH P-4569. - The only part of the tarsus preserved in NMMNH P-4569 is a partial left astragalus and complete left calcaneum. The astragalus is partially co-ossified with the calcaneum: the anterior side of the suture is completely closed and obliterated, whereas on the posterior side the suture is only partially closed, with a gap present between the two 
elements (Fig. 7.4). Both the astragalus and calcaneum are semicircular in lateral view. The astragalus possesses a short posterior pyramidal process that is the posteriormost portion of an anteroposteriorly oriented rim (visible in proximal view) that divides the tibial and fibular articular surfaces (Fig. 7.4). This rim extends to the anterior end of the astragalus, where it would form an anterior ascending process, although in this specimen the anterior process is not preserved. This posterior pyramidal process is less well defined than that of Lepidus praecisio Nesbitt and Ezcurra, 2015 (TMM 41936-1.3), which possesses a distinct notch distal to the process, and in this respect is more similar to the astragali of other early neotheropods (e.g., Coelophysis bauri, AMNH FARB 30615; Megapnosaurus rhodesiensis NHMB QG 1; Zupaysaurus rougieri, PULR 076). The posterior pyramidal process is more proximally expanded than those of early-diverging theropods (Tawa hallae, GR 242, GR unnumbered; Eodromaeus murphi, PVSJ 534; Herrerasaurus ischigualastensis, PVSJ 407). The more distinct posterior pyramidal process of NMMNH P-4569 relative to these early-diverging theropods is because in the latter taxa the astragalar proximal basin is posteriorly bordered by a ridge that in neotheropods is shifted distally (i.e., away from the tibia). The astragalus occupies less than one-third of the transverse width of the fibular articular surface, and what remains of the tibial articular facet (= astragalar proximal basin of Langer et al., 2013) indicates that this facet is much deeper than the fibular facet in proximal view. The fibular articular facet of the astragalus is V-shaped in proximal view: both the anterior and posterior portions of the proximolateral side of the astragalus extend further laterally than does the portion between them, and the calcaneum extends medially to articulate with this structure (Fig. 7.4), similar to the tarsus of M. rhodesiensis (NHMB unnumbered specimen; Langer and Benton, 2006). A poorly developed, continuous mediolaterally oriented groove is present on the posterior surfaces of the astragalus and calcaneum; in posterior view it is visible on the distalmost portion of the posterior sides of these elements. The calcaneum is roughly twice as anteroposteriorly long as it is mediolaterally wide, and the proximal portion of the calcaneum is more mediolaterally narrow than is the distal portion. The fibular articular surface of the calcaneum is concave in proximal view, and the anterior and posterior edges of this articular surface extend proximally to form shallow rims, although a similar rim is not present along the lateral side of this articular surface. Both the anterolateral and posterolateral corners of the fibular articular facet are roughly $90^{\circ}$ in proximal view, although the anterolateral corner is slightly obtuse and the posterolateral corner is slightly acute. The lateral surface of the calcaneum is covered in rough, porous bone, and a rounded ridge extends laterally along the anterodistal rim of the lateral surface of the calcaneum, defining a shallow depression on the lateral surface of the calcaneum. This depression is also present on the lateral surface of the calcaneum of Eodromaeus murphi (PVSJ 534) and Tawa hallae (GR 242) but is absent in that of Herrerasaurus ischigualastensis (PVSJ 407). The ridge on the anterodistal rim of the calcaneum of NMMNH P-4569 is also present in the calcanea of other early neotheropods (e.g., $C$. bauri, AMNH FARB 30615; M. rhodesiensis, NHMB QG 1; Lepidus praecisio, TMM 41936-1.3; Camposaurus arizonensis Hunt et al., 1998, UCMP 34498).
Apart from size, what is preserved of the astragalus and calcaneum is largely indistinguishable from those of most coelophysoids, Zupaysaurus (Ezcurra and Brusatte, 2011; Nesbitt and Ezcurra, 2015) and Dilophosaurus wetherilli (Welles, 1984). Although the articulation between the astragalus and calcaneum is obscured by the partial fusion of these elements, it is clear in posterior view (Fig. 7.4) that the lateral process of the astragalus of NMMNH P-4569 is not laterally expanded to the same extent as in the astragalus of Eodromaeus murphi (PVSJ 534), so that the majority of the articular surface for the fibula of NMMNH P-4569 is formed from the calcaneum, and the posterior pyramidal process nearly abuts the calcaneum (Fig. 7.4). The calcaneum of NMMNH P-4569 and other neotheropods is reduced relative to that of Herrerasaurus ischigualastensis (PVSJ 407; Langer and Benton, 2006), which possesses a posterolaterally projecting calcaneal tuber and a medial process that is also present in Eoraptor lunensis Sereno et al., 1993 (Sereno et al., 2013; fig. 88). However, in contrast to most other theropods (including NMMNH P-4563), the calcaneum of Tawa hallae (GR 242, GR unnumbered; Nesbitt et al., 2009) is reduced more than that of neotheropods to only a mediolaterally and proximodistally narrow sliver of bone. The calcaneum of Eodromaeus murphi (PVSJ 534) is also more morphologically complex than that of neotheropods, with a tuber projecting from the posterolateral corner of the calcaneum and a posteromedial notch for articulation with a laterally projecting process on the posterolateral end of the astragalus. However, like NMMNH P-4569, there is a shallow mediolaterally oriented groove on the posterodistal side of the astragalus and calcaneum of $E$. murphi.

Pes of NMMNH P-4569. - The pes of NMMNH P-4569 is represented by the distal end of the left metatarsal IV, the anterodistal portion of the right metatarsal II, one complete (but partially damaged) proximal phalanx, and other less complete phalanges. Metatarsal II is identifiable by the asymmetry of the articular condyle in anterior view (Fig. 8.1), and the lateral collateral ligament pit of this element is very deep $(\sim 1 \mathrm{~cm}$ from the lateral edge of the metatarsal; Fig. 8.1), with the lateral portion of the articular condyle extending distally further than the medial portion. The medial collateral ligament pit is far shallower than the lateral pit, and the anterior surface bears the distal portion of the extensor pit (Fig. 8.1).

The left metatarsal IV is identifiable by the asymmetrical articular condyle, with a lateral flange most prominent in distal view (Fig. 8.2). The distal end of metatarsal IV possesses a ligament pit on the medial surface of the articular condyle and a shallow scar for the insertion of ligaments on the lateral surface of the condyle. The asymmetry of the distal condyle of metatarsal IV in distal view is a synapomorphy of the clade Silesauridae + Dinosauria (Nesbitt et al., 2009; Nesbitt, 2011). In NMMNH P-4569, the lateral surface of the condyle possesses a posterolaterally extending flange beneath the ligament insertion scar, whereas the medial portion of the condyle is rounded and anteroposteriorly tall in medial view; this results in a roughly triangular morphology in distal view (Fig. 8.2). The posterior side of the articular condyle possesses a proximodistal groove. 
Although the largest phalangeal elements are clearly pedal elements, and the smallest clearly manual elements, distinguishing midsized partial phalanges as either larger manual phalanges or smaller pedal phalanges is uncertain. I therefore describe all phalanges not easily identifiable as manual phalanges in this section. The proximal articular surface of the complete proximal phalanx is dorsoventrally concave, resulting in the articular surface appearing U-shaped in lateral view (Fig. 9.3). The dorsal part of the rim of the articular surface possesses a rounded, poorly developed 'apex' in proximal view, and the medial and lateral portions of the rim have similar apexes. The ventral portion of the rim has two equally spaced, rounded apexes separated by a shallow depression. These irregularities in the rim of the articular surface create a broadly pentagonal shape in proximal view. The proximal articular surface is slightly dorsoventrally compressed, and the articular surface is wider than any portion of the shaft of the phalanx. The phalanx narrows immediately distal to the proximal articular surface. Two small foramina are present on the ventral surface of the shaft, midway between the proximal and distal surfaces. The articular condyle of the distal end of the phalanx forms a smooth, continuous rounded surface, and the medial and lateral sides possess deep collateral ligament pits. On the dorsal surface of the phalanx, immediately proximal to the articular condyle, a depression (= extensor pit) separates the articular condyle from the shaft of the phalanx. The condylar portion of the phalanx is mediolaterally wider than the shaft. The other, incomplete proximal phalanx is identical to the complete phalanx, except in mirror image, and therefore likely belongs to the opposite limb. Because these proximal phalanges are similar to those of other early neotheropods (e.g., Megapnosaurus rhodesiensis Raath, 1977; Dilophosaurus wetherilli, Welles, 1984; Coelophysis bauri, Colbert, 1989) as well as nonneotheropod theropods (e.g, Tawa hallae, unnumbered GR specimen), early sauropodomorphs (e.g., Eoraptor lunensis, Sereno et al., 2013), and silesaurids (e.g., Asilisaurus kongwe, NMT RB159), this phalanx morphology is likely the plesiomorphic condition for Dinosauria.

All that is preserved of the distal (?pedal) phalanges are the proximal articular ends, and these are roughly triangular in proximal view in that they are dorsoventrally taller than mediolaterally wide (Fig. 8.3-8.5). The ventral portion of this articular surface is widest, and a dorsoventrally oriented ridge connects the dorsal and ventral intercondylar processes in each phalanx, separating the medial and lateral cotyli. The medial and lateral cotyli are not symmetrical, so the ridge does not extend anteriorly across the exact middle of the proximal articular surface of these phalanges. The ventral surfaces of the proximal end of these phalanges are flat, with rugose ridges on the proximalmost edges of these surfaces (Fig. 8.3-8.5). The shafts of these phalanges are mediolaterally compressed, and the dorsal intercondylar processes transition into subtle dorsal ridges on the shafts of these elements. The more distal phalanges are nearly identical but are proximodistally shortened to such a degree that they lack a shaft, instead transitioning directly from the proximal articular surface to the distal articular condyle of the phalanx (Fig. 8.6).

Fibula of NMMNH P-4563.-NMMNH P-4563 consists of an isolated proximal end of a left fibula in two pieces (Fig. 10), along with a third small piece from somewhere on the midshaft (not figured; Griffin and Nesbitt, in press). The maximum anteroposterior width of the head of this fibula is $59.43 \mathrm{~mm}$, which makes it roughly the same size as Liliensternus liliensterni and Zupaysaurus rougieri (Griffin and Nesbitt, in press, fig. 1). The proximalmost portion of the fibula is anteroposteriorly expanded relative to the shaft, the medial surface of the fibula is slightly concave in medial view, and the lateral surface is slightly convex. The proximal end of the fibula is mediolaterally wider anteriorly than posteriorly, and the anterior portion of the proximal end of the fibula extends proximally further than the posterior portion in lateral view (Fig. 10.1). The proximalmost portion of the fibula is anteroposteriorly wider than most of the shaft of the fibula in medial and lateral view. The posteromedial portion of the proximal end of the fibula possesses a thin ridge that originates $\sim 1.5 \mathrm{~cm}$ distal to the proximal surface, medially bordering a shallow sulcus on the posterior end of the proximal portion of the fibula, and extends distally on the medial edge of the posterior side of the fibula. This thin ridge is widespread among early neotheropods as it is present in Megapnosaurus rhodesiensis (NHMB QG 1), Coelophysis bauri (AMNH FARB 7223, 7224), the 'Padian' Coelophysis (UCMP 129618), and Liliensternus liliensterni (HMN BM.R.2175) but is absent in Tawa hallae (unnumbered GR specimen). This ridge is present in Eodromaeus murphi, but unlike in neotheropods it extends across the posterior portion of the medial surface of the proximal end of the fibula (PVSJ 562 ).

The thick ridge on the medial surface of the proximal portion of the fibula is medially extended and clearly differentiated from the rest of the medial surface of the fibula; it extends from just distal to the articular surface on the medial side for $\sim 5 \mathrm{~cm}$ anterodistally (Fig. 10.3) and terminates on the anterior end of the medial side of the fibular shaft, $\sim 6 \mathrm{~cm}$ distal to the proximal surface of the fibula. This ridge is bordered distally by a welldefined sulcus (Fig. 10.3). The medial side of the fibular shaft is concave, and the ridge on the posterior side trends anteriorly across the distal portion of the deep medial sulcus (Fig. 10.3). The lateral side of the fibular shaft is convex. The distalmost end of this medial scar intersects a rugose, raised anteromedial surface of the fibula, and this raised anteromedial portion causes the anterior side of the fibula to be mediolaterally thicker than the posterior side. This rugose anteromedial surface wraps anterodistally around the shaft of the fibula to the iliofibularis tubercle, which is a raised flange on the anterolateral side of the shaft of the fibula; this rugose surface may be an extension of the iliofibularis tubercle. The rugose texture associated with the iliofibularis tubercle extends across the anterior side of the fibular shaft to the medial surface of the fibula (Fig. 10.1-10.3). The thick ridge on the medial surface of the fibula is widespread among early neotheropods (Rauhut, 2003) and has been recovered as a synapomorphy of Neotheropoda (Nesbitt et al., 2009). The large size of NMMNH P-4563 makes this scar more distinct than in Coelophysis and Megapnosaurus, but it is morphologically similar to the same scar in these taxa. Liliensternus liliensterni (HMN BM.R.2175) lacks this scar, but because this scar is ontogenetically variable among early neotheropods (Griffin, 2018), this absence may relate to the skeletal immaturity of 
this individual (Griffin and Nesbitt, in press). Morphologically similar scars, though less well defined and rugose, are present in the fibulae of the early theropods Eodromeaus murphi (PVSJ 562) and Herrerasaurus ischigualastensis Reig, 1963 (Novas, 1993, fig. 8F) and the sauropodomorph Saturnalia tupiniquim Langer et al., 1999 (Langer, 2003), although this scar in E. murphi is closer to the neotheropod condition. In addition, a similar light scar is present in the medial surface of the proximal end of the fibula of the dinosauriform Asilisaurus kongwe Nesbitt et al., 2010 (NMT RB159).

The raised, rugose portion of the anteromedial edge of the fibula that is potentially an expansion of the iliofibularis tubercle is present in NMMNH P-4563 but absent in all other earlydiverging neotheropods for which the proximal ends of fibulae are known, including the large-bodied L. liliensterni (HMN BM.R.2175) and robust, skeletally mature individuals of $C$. bauri (e.g., AMNH FARB 7223, 7224) and M. rhodesiensis (e.g., NHMB QG 1). Madsen and Welles (2000, pl. 23) interpret a large, rounded, proximodistally elongate ridge on the anteromedial surface of the fibular shaft of Ceratosaurus Marsh, 1884 as a portion of the iliofibularis tubercle (= 'tibial flange' of Madsen and Welles, 2000); this large ridge is similar in location to the rugose raised portion of the fibular anteromedial edge of NMMNH P-4563. The fibula of Herrerasaurus ischigualastensis possesses a round scar on the medial side of the fibular shaft level with the iliofibularis tubercle (Novas, 1993); however, this scar does not extend proximally up the anteromedial edge of the fibula as in NMMNH P-4563. Rugose texture is present on the anterior edge of the fibula of a large individual of Asilisaurus kongwe (NMT RB159), just proximal and distal to the distal termination of the medial scar; however, this rugose texture does not extend distally on the shaft nearly as far as in NMMNH P-4563, in which it is continuous with the iliofibularis tubercle. If NMMNH P-4563 represents another individual of Gojirasaurus quayi, then this raised rugosity may be a diagnostic character for this taxon; however, the histology of this fibula is suggestive of a pathology, potentially a fracture callus (Griffin, in press), so the distinctive morphology of this rugose ridge may be related to this pathology rather than an apomorphic character state.

The overall morphology of the proximal portion of the fibula of NMMNH P-4563 is similar to those of other early-diverging neotheropods (e.g., Coelophysis bauri, AMNH FARB 7223, 7224; Megapnosaurus rhodesiensis, NHMB QG 1; 'Padian' Coelophysis, UCMP 129618; Liliensternus liliensterni, HMN BM.R.2175; Dilophosaurus wetherilli, UCMP 37302). The proximal ends of the fibulae of these neotheropods differ from the fibulae of Tawa hallae (Nesbitt et al., 2009) and Eodromaeus murphi (Martinez et al., 2011) in that in the latter taxa the proximalmost end of the fibula does not expand anteroposteriorly far beyond the fibular shaft in lateral view.

Metatarsal $V$ of Gojirasaurus quayi.-Besides a partial shaft of a metatarsal, the pes of Gojirasaurus quayi (UCM 47221) is represented by a left metatarsal $\mathrm{V}$ that was not described with the rest of the material comprising this specimen (Carpenter, 1997). Like metatarsal V of other neotheropods, this roughly $10.5 \mathrm{~cm}$ long element is splint-like and, judging from the lack of distal articular condyle, the fifth pedal digit probably possessed no phalanges, similar to the majority of other bird-line archosaurs (Nesbitt, 2011). It is anteroposteriorly thickest midway between the proximal and distal surfaces and thins to a rounded point distally. It is slightly anteriorly and medially curved (Fig. 11) in lateral and posterior views and is mediolaterally thickest at its proximal end. This end is triangular in proximal view, with tubera on the lateral, posteromedial, and anteromedial portions of the proximal end (Fig. 11.5). Roughly one-fourth of the distance from the proximal surface, the element shifts from an anteroposteriorly oriented maximum width to a mediolaterally oriented maximum width as the lateral tuber of the proximal end becomes less pronounced before disappearing. On the posterior surface of the proximal portion, a low proximodistally oriented ridge originates from the lateral tuber and extends distally across the medial edge of the metatarsal in posterior view. There is an elliptical bone scar on the anterior surface of metatarsal V that extends anteriorly from the edge of the element (Fig. 11.1, 11.2). This element has not often been described in detail in early neotheropods, but the metatarsal $\mathrm{V}$ of Megapnosaurus rhodesiensis possesses a sulcus on its anterior surface instead of a raised scar in addition to a shallow, wide sulcus on its proximomedial surface that G. quayi lacks, and Raath (1977) interprets these to be insertion scars of muscles, tendons, or ligaments. Metatarsals V of Liliensternus liliensterni, Zupaysaurus rougieri, Lophostropheus airelensis, and Cryolophosaurus ellioti are not known. Dilophosaurus wetherilli possesses a roughly similar metatarsal $\mathrm{V}$, but in this taxon the proximal end is convex between the lateral and anteromedial tubera (Welles, 1984), unlike in G. quayi, in which it is straight. Overall, the metatarsal V of G. quayi is proportionally thicker than that of M. rhodesiensis, but only with more detailed descriptions of the neotheropod metatarsal $\mathrm{V}$, especially in other large taxa, can these features be determined to be apomorphic for G. quayi.

\section{Phylogenetic analysis and ancestral state reconstruction}

I scored the holotype of Gojirasaurus quayi (UCM 47221) and the Bull Canyon neotheropod specimens (NMMNH P-4569; NMMNH P-4563) separately and as one taxon (Gojirasaurus quayi) using the matrix of Nesbitt and Ezcurra (2015), which was in turn modified from Ezcurra and Brusatte (2011) and Nesbitt et al. (2009). I also added Panguraptor lufengensis to this matrix, following the scoring of You et al. (2014) and scoring the four characters added by Nesbitt and Ezcurra (2015) as missing data because I could not score these characters in this taxon. I assembled this matrix comprising 53 taxa and 364 characters with the terminal taxon G. quayi coded from all three specimens (UCM 47221, NMMNH P-4569, and P-4563) in Mesquite (Maddison and Maddison, 2016) before analyzing it in PAUP* (v. 4.0b10; Swofford, 2002). I also ran analyses with these specimens separated into different terminal taxa (see the following).

I searched for most-parsimonious trees with the heuristic search option using tree bisection and reconnection (TBR) with 10,000 random addition sequence replicates, and branches 
of zero length were collapsed. All characters were equally weighted, and characters $17,30,67,128,174,184,213,219$, $231,236,248,253,254,273,329$, and 343 were ordered. I calculated tree statistics in TNT (Goloboff and Catalano, 2016), including both bootstrap levels and Bremer decay indices, and bootstrap levels were calculated using 10,000 bootstrap replicates with 10 random addition sequence replicates for each bootstrap replicate. The 12 most-parsimonious trees recovered by TNT (using a traditional search with Wagner trees, 1 random seed, and 100 replications, using the tree bisection reconnection algorithm and saving 100 trees per replication) were identical to those recovered by PAUP*, as was the resulting strict consensus tree. Bremer support indices were calculated in TreeRot (Sorenson, 1999).

The phylogenetic analysis returned 12 most-parsimonious trees (MPTs) with tree lengths of 1,061 steps, and I used these to form a strict consensus tree (Fig. 12) in both analyses (i.e., in PAUP* and TNT) that included the three specimens as one terminal taxon (Gojirasaurus quayi). I recovered Eoraptor lunensis as the sister taxon to all other sauropodomorphs (as did Martinez et al., 2011; Nesbitt and Ezcurra, 2015) and Chindesaurus bryansmalli Long and Murray, 1995 as more closely related to Neotheropoda than to Herrerasauridae (as did Nesbitt and Ezcurra, 2015). 'Syntarsus' kayentakatae Rowe, 1989 is the basalmost coelophysoid in the strict consensus tree, and Camposaurus arizonensis and Megapnosaurus rhodesiensis are sister taxa within Coelophysoidea. Gojirasaurus quayi, Liliensternus liliensterni, and Zupaysaurus rougieri are unresolved at the base of Neotheropoda in the strict consensus, and Dilophosaurus wetherilli was recovered as closer to Averostra than Cryolophosaurus ellioti. All other relationships were identical to those found by Nesbitt et al. (2009), Ezcurra and Brusatte (2011), and Nesbitt and Ezcurra (2015). The relationships recovered by the Adams consensus tree (calculated in PAUP*) was identical to the strict consensus tree except for the placement of $L$. liliensterni and Z. rougieri. Instead of forming a polytomy with Gojirasaurus at the base of Neotheropoda, L. liliensterni was recovered as the basalmost coelophysoid, and Z. rougieri was recovered as the sister taxon of the clade Cryolophosaurus + Averostra.

The same analysis in PAUP*, conducted on a matrix with the Gojirasaurus holotype (UCM 47221) and the partial Bull Canyon neotheropod skeleton (NMMNH P-4569) scored as separate terminal taxa and that excluded the isolated neotheropod fibula (NMMNH P-4569) recovered 89 equally parsimonious trees. The strict consensus and Adams consensus of these trees were identical to each other. These trees were also identical to the strict consensus of the trees recovered by treating the NMMNH specimens as Gojirasaurus quayi, except that NMMNH P-4569 was recovered in a polytomy with G. quayi, Liliensternus, and Zupaysaurus at the base of Neotheropoda (Supplementary data, Fig. S1). Another analysis in PAUP*, this time including the isolated fibula (NMMNH P-4563) and excluding the partial neotheropod skeleton (NMMNH P-4569) recovered 204 equally parsimonious trees. The strict consensus of these trees retained Coelophysoidea identically to the other strict consensus trees (with 'Syntarsus' kayentakatae as the basalmost member) but placed all other neotheropods in a single large polytomy with Eodromaeus murphi (Supplementary data,
Fig. S2). The Adams consensus of these 204 trees was identical to the Adams consensus where all three specimens were scored as a single terminal taxon, except that Eodromaeus was recovered in a polytomy with Gojirasaurus and NMMNH P-4563 at the base of Neotheropoda, Zupaysaurus and Cryolophosaurus were in a polytomy outside of Cryolophosaurus + Averostra, and Dilophosaurus and Cryolophosaurus were in a polytomy with Averostra (Supplementary data, Fig. S3).

Femur length has been often used as a proxy for body size in theropods (Christiansen and Fariña, 2004; Benson et al., 2012; Carrano, 2006; Novas et al., 2012; Sookias et al., 2012; Turner and Nesbitt, 2013; Lee et al., 2014; Puttick et al., 2014; Griffin and Nesbitt, 2016) because it is readily available from the literature and often easily measured/estimated. Although there is some uncertainty in predicting body mass in extinct organisms (Seebacher, 2001; Alexander, 2006; but see Campione and Evans, 2012; Campione et al., 2014), limb bone shaft circumference is known to be an overall better metric than femoral length for estimating body mass (e.g., Campione and Evans, 2012), and body mass is preferable for absolute comparison of body size across disparate taxa. Femoral length does not scale directly to body mass, so relative differences in femur length cannot be scaled to differences in absolute body mass: for example, Liliensternus liliensterni has a femoral length of $424 \mathrm{~mm}$ (Supplementary data, Table S1) and an estimated mass of $84 \mathrm{~kg}$ (Benson et al., 2018), whereas Gojirasaurus has an estimated femur length of only $11 \mathrm{~mm}$ longer (Supplementary data, Table S1), but an estimated mass of $190 \mathrm{~kg}$ (Benson et al., 2014, 2018). However, using the regressions of Griffin and Nesbitt (2016), I am able to estimate femoral length for fragmentary individuals that lack complete femora (e.g., Zupaysaurus, NMMNH P-4569; Supplementary data, Table S1), which allows for quantitative comparison of a body size metric (i.e., femoral length) between fragmentary taxa that might lack the measurements (e.g., femoral shaft circumference) most commonly used to predict body mass (e.g., Campione and Evans, 2012; Benson et al., 2014). In addition, even though femoral lengths are not a good absolute measure of body mass, they can be useful for determining relative sizes among closely related taxa with similar body proportions (i.e., early neotheropods). Even though body mass is not calculable in several individuals used in this study, I have referenced body masses as estimated in Benson at al. $(2014,2018)$ in brackets after femoral lengths for applicable taxa to give absolute comparative size data where available.

To reconstruct the ancestral femoral length of both Theropoda and Neotheropoda, I used the ancestral state reconstruction function anc.ML() in the package phytools (Revell, 2012) in R (R Development Core Team, 2008), which estimates ancestral states for Brownian evolution using maximum likelihood. To calculate branch lengths, I used six taxa (Coelophysis bauri, Cryolophosaurus ellioti, Zupaysaurus rougieri, Eodromaeus murphi, Staurikosaurus pricei Colbert, 1970, and Saturnalia tupiniquim) as calibration points, arbitrarily setting their branch lengths as 1 million years. I then found the age of unconstrained nodes by dividing the age of the closest calibrated node by the number of internodes separating this calibrated node from the closest calibrated taxon. Once the age of each node was assigned, branch lengths of all taxa could be assigned. This 


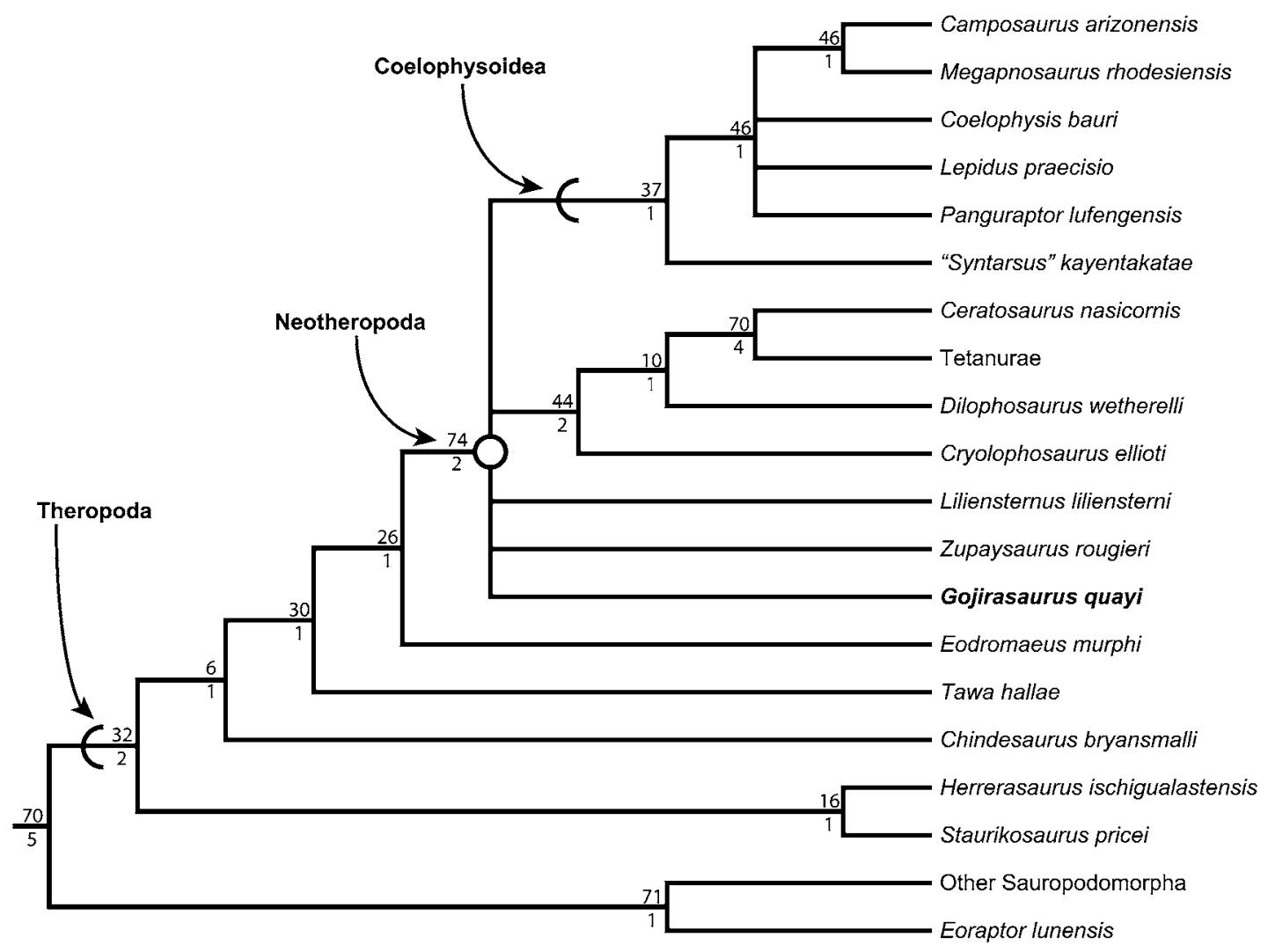

Figure 12. Strict consensus tree of 12 most parsimonious trees (MPTs) recovered by the phylogenetic analysis (tree length $=1062$; consistency index $=0.386$; retention index $=0.691$, taken from most parsimonious tree 1 of 12), highlighting the phylogenetic position of Gojirasaurus quayi (UCM 47221, NMMNH P-4563, and P-4569, coded as one terminal taxon). Absolute bootstrap frequencies for each node are indicated above the relevant node, and Bremer support indices are beneath each node.

method of 'smoothing' the time between clade divergences avoids the calculation of infinite rates of evolution at unconstrained nodes and is widely used in paleontology (Ruta et al., 2006; Brusatte et al., 2008; Nesbitt et al., 2009; Irmis, 2011; Sookias et al., 2012; Turner and Nesbitt, 2013). This analysis reconstructed the common neotheropod ancestor as larger than most coelophysoids and early-diverging theropods, with a reconstructed femoral length between 300 and $340 \mathrm{~mm}$ (slightly smaller than, e.g., Liliensternus, femoral length $424 \mathrm{~mm}$ [84 kg]; Fig. 13; Table 1). Coelophysis bauri, Megapnosaurus rhodesiensis, and other coelophysoids, especially the more derived members of this clade, were reconstructed as being secondarily small-bodied. The ancestral theropod body size was reconstructed as small, with Herrerasaurus reaching its large size independently of more-derived theropods (Fig. 13).

Because Liliensternus and Zupaysaurus have been recovered at different phylogenetic locations across the base of Neotheropoda in different analyses (Carrano et al., 2005; Tykoski, 2005; Yates, 2005; Ezcurra and Cuny, 2007; Ezcurra and Novas, 2007; Nesbitt et al., 2009; Sues et al., 2011; You et al., 2014; Ezcurra, 2017), I wanted to test how their location changed reconstructed ancestral states. I added the combined Gojirasaurus quayi terminal taxon (UCM 47221, NMMNH P-4569; NMMNH P-4563) to the matrix of Ezcurra (2017), which is based on and expanded from those of Nesbitt et al. (2009), Ezcurra and Brusatte (2011), and Nesbitt and Ezcurra (2015). The analysis was conducted in PAUP* as previously described. Although the original analysis by Ezcurra (2017) recovered Liliensternus and Zupaysaurus in a polytomy with all other neotheropods, similar to other recent analyses conducted (including my own), the addition of Gojirasaurus as a terminal taxon resulted in 12 MPTs, which when summarized as both strict and Adams consensus trees result in the largerbodied Triassic neotheropods being recovered as more closely related to Averostra than to Coelophysoidea (Supplementary data, Fig. S4). Because of this difference between Ezcurra (2017) and other recent analyses, I used the methods described to reconstruct ancestral femoral lengths with these new relationships from the first MPT recovered from the PAUP* analysis. Most of the reconstructed ancestral states are extremely similar to the previous analysis, but because of the relationships of the large-bodied Triassic taxa, the size increase does not occur at the base of Neotheropoda, with the coelophysoids being secondarily small-bodied; instead, the size increase occurs solely on the lineage to Averostra (Supplementary data, Fig. S5).

\section{Discussion}

The skeletal morphology of NMMNH P-4569, especially the lack of co-ossification between several elements (e.g., pubis and ilium, astragalus and calcaneum), strongly suggests that it is skeletally immature. This suite of ontogenetic character states seen in this individual is only present in very immature individuals of Coelophysis bauri and Megapnosaurus rhodesiensis, 


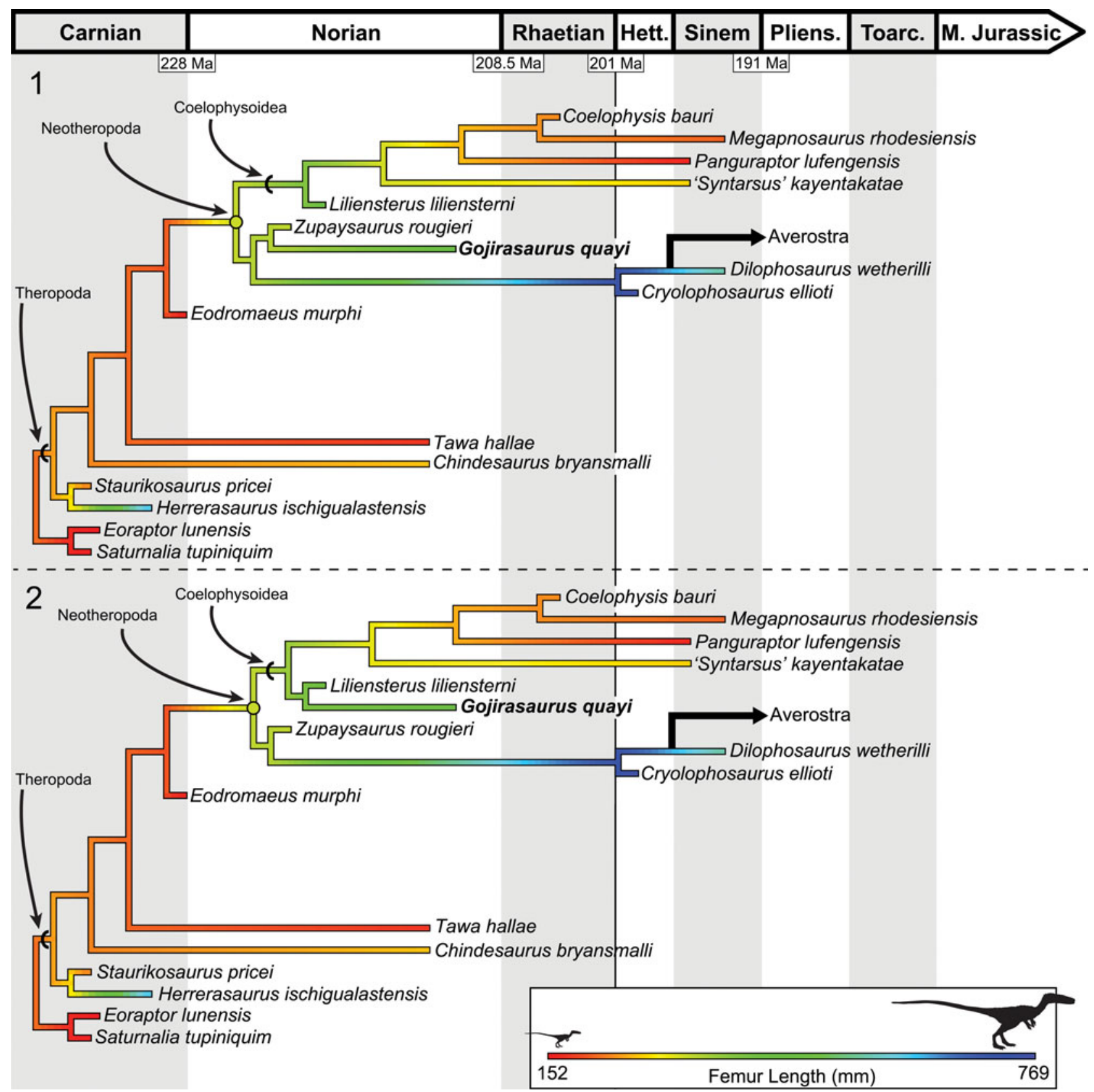

Figure 13. Results of the ancestral state reconstruction of femur length among early-diverging theropods, suggesting that the ancestral body size for Theropoda was small but that the common neotheropod ancestor was larger and that coelophysoids experienced secondary reduction in body size. (1) Ancestral state reconstruction using MPT 1 of 12. (2) Ancestral state reconstruction using MPT 2 of 12. Note that the neotheropod ancestral state shifts depending on the position of Gojirasaurus. Femoral size scale is the same for both trees. Reconstructed ancestral femoral lengths are available in Table 1.

and most of these ontogenetic characters are phylogenetically bracketed by coelophysoids and ceratosaurs (Griffin, 2018). This maturity assessment of the Bull Canyon neotheropods has been corroborated by bone histology, which suggests that these individuals had not neared asymptotic size before death (Griffin and Nesbitt, in press). It is now clear that our knowledge of large, nonaverostran neotheropods comes exclusively from a few skeletally immature individuals, with Zupaysaurus, Liliensternus, and Gojirasaurus all represented by partial, ontogenetically immature specimens (Welles, 1984; Tykoski, 1998, 2005; Griffin and Nesbitt, in press), in addition to the Early Jurassic taxa Dilophosaurus wetherilli (Welles, 1984; Tykoski, 1998)
Lophostropheus airelensis Ezcurra and Cuny, 2007, and Cryolophosaurus ellioti (Smith et al., 2007), all of which possess skeletal characters suggestive of immaturity. Skeletally immature individuals are commonly recovered at a different phylogenetic position (usually as more early diverging) than skeletally mature individuals of the same taxon (e.g., Butler and Zhao, 2009; Evans et al., 2011; Fowler et al., 2011; Tsuihiji et al., 2011; Campione et al., 2013; Tsai and Fordyce, 2014), and so the lack of resolution in my phylogenetic analysis (Fig. 12) may be in part because many of the poorly resolved taxa are only known from partial, immature individuals. Alternatively, this lack of resolution may be systemic of all phylogenies of 
Table 1. Reconstructed ancestral states for early saurischian clades using MPT 1 and 2.

\begin{tabular}{lcc}
\hline Node & $\begin{array}{c}\text { Reconstructed ancestral femoral } \\
\text { length, MPT 1 (mm) }\end{array}$ & $\begin{array}{c}\text { Reconstructed ancestral femoral } \\
\text { length, MPT 2 (mm) }\end{array}$ \\
\hline Sauropodomorpha+ Theropoda & 217.1 & 217.4 \\
Eoraptor+ Saturnalia & 168.9 & 168.9 \\
Theropoda & 241.3 & 241.6 \\
Herrerasauridae & 273.3 & 273.5 \\
Chindesaurus + Neotheropoda & 224.1 & 225.0 \\
Tawa + Neotheropoda & 202.4 & 203.9 \\
Eodromaeus + Neotheropoda & 184.0 & 186.4 \\
Neotheropoda & 296.1 & 341.9 \\
Coelophysoidea & 331.2 & 386.6 \\
'Syntarsus' kyentakatae + Coelophysis & 287.7 & 327.8 \\
Panguraptor + Coelophysis & 247.1 & 276.0 \\
Zupaysaurus + Dilophosaurus & 353.4 & 374.6 \\
Cryolophosaurus + Dilophosaurus & 715.8 & 720.3 \\
\hline
\end{tabular}

early theropods. There is disagreement between recent cladistic analyses on the phylogenetic placement of many of these taxa, with Liliensternus and Zupaysaurus recovered as more closely related to Coelophysis bauri (Carrano et al., 2005; Tykoski, 2005; Yates, 2005; Ezcurra and Cuny, 2007; Ezcurra and Novas, 2007; You et al., 2014) or Averostra (Yates, 2005; Nesbitt et al., 2009; Sues et al., 2011; Supplementary data, Fig. S4). Dilophosaurus has been recovered as just outside Averostra (Yates, 2005; Smith et al., 2007; this study) or as a coelophysoid (Carrano et al., 2012), and Cryolophosaurus has been recovered as either outside (Smith et al., 2007) or within Averostra (Carrano et al., 2012). In addition, recent analyses have even proposed conflicting interrelationships between Sauropodomorpha and Theropoda (Cabreira et al., 2016; Baron et al., 2017). This disagreement between analyses may also be in part because of a reliance on immature individuals for terminal taxa.

The ancestral theropod is thought to have been smallbodied (roughly the size of, e.g., Tawa hallae, femur length = $176 \mathrm{~mm}$ [3.2 kg], Coelophysis bauri, femur length $\sim 220 \mathrm{~mm}$ [9.8 kg]; Langer and Benton, 2006; Brusatte et al., 2010b; Irmis, 2011; Benson et al., 2014). Statistical analysis of the extensive theropod track record from eastern North America has suggested that these theropods did not evolve large body sizes (comparable to Dilophosaurus, femur length $\sim 557 \mathrm{~mm}$ [350 kg]) until the Early Jurassic (Olsen et al., 2002). However, more recent work suggests this is not a worldwide trend (Irmis, 2011; Benson et al., 2012, 2014; Griffin and Nesbitt, in press). Ancestral state reconstruction of body size in this clade adds further nuance to understanding the early evolution of large body sizes among theropods. Instead of the common neotheropod ancestor possessing a small, Coelophysis-like body size $(\sim 10 \mathrm{~kg})$, common among most early theropods (e.g., Tawa hallae Nesbitt et al., 2009; Eodromaeus murphi Martinez et al., 2011; Daemonosaurus chauliodus Sues et al., 2011) and most coelophysoids (Megapnosaurus rhodesiensis Raath, 1977; Griffin, 2018; 'Syntarsus' kayentakatae Rowe, 1989; Tykoski, 1998; Segisaurus halli Camp, 1936; Carrano et al., 2005; Panguraptor lufengensis You et al., 2014; Lepidus praecisio Nesbitt and Ezcurra, 2015; Camposaurus arizonensis Ezcurra and Brusatte, 2011; Dracoraptor hanigani Martill et al., 2016; the Padian Coelophysis, UCMP 129618; the Hayden Quarry coelophysoid, GR 227), the reconstructed femoral size for this common ancestor is larger ( 300-340 mm; Irmis, 2011; Benson et al., 2014) in this study, over $150 \%$ the femoral length of the largest known individual of Coelophysis bauri ( $10 \mathrm{~kg}$; Fig. 13; Supplementary data, Table S1). The phylogenetic location of Gojirasaurus (estimated femur length $=435 \mathrm{~mm}[190 \mathrm{~kg}]$ ), a taxon not used in most previous analyses of body size (but see Benson et al., 2018), affects the reconstructed Neotheropod ancestral size: if Gojirasaurus is recovered as an early-diverging coelophysoid, the ancestral neotheropod is reconstructed as smaller than if Gojirasaurus is found as more closely related to Averostra (Fig. 13; Table 1), and if the three larger-bodied Triassic neotheropods are recovered as closer to Averostra than to Coelophysoidea, then the common neotheropod ancestor is recovered as relatively small (Supplementary data, Fig. S5). In addition, because the five largest neotheropod body sizes in this analysis were taken from immature individuals that had not reached full body size, and probably reached Dilophosaurus-like body sizes (Griffin and Nesbitt, in press), this reconstructed state represents a lower bound on the estimated ancestral neotheropod body size. During its evolutionary radiation, Coelophysoidea did not retain the large body size ancestral for Neotheropoda throughout the Late Triassic into the Early Jurassic, but instead experienced a secondary decrease in body size to those similar to the closest neotheropod relatives, Tawa and Eodromaeus (Fig. 13; qualitatively hypothesized by Carrano et al., 2006 from the phylogenetic position of Dilophosaurus with respect to coelophysoids).

This study and others exploring the early evolution of body size among theropods (Irmis, 2011; Benson et al., 2012, 2014, 2018; Turner and Nesbitt, 2013) have recovered largely similar results, with a small ancestral theropod and an increase to larger sizes prior to the Early Jurassic. By contrast, another recent analysis found the ancestral theropod femoral length to be extremely large $(478 \mathrm{~mm})$, with the ancestral femoral length for the clade Tawa + Neotheropoda and for Neotheropoda just as large (476 and $475 \mathrm{~mm}$, respectively; Lee et al., 2014). Although this reconstructed theropod body size is not feasible compared with my and all other recent reconstructions, the neotheropod ancestral size recovered by Lee et al. (2014) may actually be plausible, but only given that all large Triassic neotheropod taxa are known from immature individuals and may have reached Dilophosaurus-like sizes at skeletal maturity (Griffin and Nesbitt, in press), which would increase the reconstructed size at this node. Therefore, sampling at the base of the theropod tree biased toward larger-bodied taxa in the analysis of Lee et al. (2014) has inflated the reconstructed body size of early Theropoda (Benson et al., 2018). Herrerasaurus (femur 
length $=482 \mathrm{~mm}[260 \mathrm{~kg}]$ ) was used as the basalmost theropod in the analysis, with Tawa as the next theropod closer to Aves (Lee et al., 2014, figs. 1, S1). Thus, this analysis is missing Eoraptor (as either an outgroup or basalmost theropod) and other nonneotheropod theropods to better constrain the early evolution of body size in this group. The addition of these taxa in my analysis and others' (Irmis, 2011; Benson et al., 2012, 2014, 2018; Turner and Nesbitt, 2013) shows that the large body size of Herrerasaurus is derived within Herrerasauridae and not ancestral for Theropoda, even with the much larger femoral length for Herrerasaurus included in my analysis (Fig. 13; Supplementary data). Tawa would have helped to better constrain these reconstructions in Lee and colleagues' (2014) analysis, but no femoral data were recorded for this taxon and it is classified as 'large' (Lee et al., 2014, figs. 1, S1) despite its status as one of the smaller known early theropods (Fig. 13, Table 1). Among early neotheropods, 'Syntarsus' kayentakatae, Cryolophosaurus ellioti, and Dilophosaurus wetherilli (all recovered as ceratosaurians) were included in Lee and colleagues' (2014) analysis, and the absence of the majority of smaller neotheropods and earlydiverging theropods (reviewed by Benson et al., 2018) inflates the reconstructed ancestral sizes to such a degree that the common ancestors of Theropoda are considered to be larger than any morederived common ancestor along the entire theropod lineage. Denser sampling near the base of Theropoda gives results that are more consistent with other studies (Irmis, 2011; Benson et al., 2012, 2014; Turner and Nesbitt, 2013) and suggest that the earliest theropods were small and that body size increased greatly in this lineage during the first $10-30$ million years of its evolution in the Late Triassic, with early neotheropods reaching much larger body sizes than the common theropod ancestor and coelophysoids evolving secondarily small body sizes.

\section{Conclusions}

The Bull Canyon specimens (NMMNH P-4563, P-4569) are earlydiverging neotheropods and, judging from several morphological characters known to be ontogenetically variable in other earlydiverging neotheropods, represent skeletally immature individuals. The phylogeny of early Neotheropoda is poorly resolved, and this may be from a reliance on incomplete, ontogenetically immature specimens, or this lack of resolution may be systemic for all phylogenies of early theropods. My ancestral state reconstruction suggests that the ancestral theropod body size was relatively small ( $240 \mathrm{~mm}$ femur length; $\sim 10 \mathrm{~kg}$ ) but that body size increased substantially in early Neotheropoda ( $300-340 \mathrm{~mm})$, with coelophysoid neotheropods experiencing secondary reduction in body size, consistent with most other published analyses. Because large Triassic neotheropods are known exclusively from skeletally immature individuals (Griffin and Nesbitt, in press), this ancestral body size for Neotheropoda represents a lower bound on this ancestral state. Theropod dinosaurs had evolved large body sizes before the Triassic-Jurassic mass extinction but were rare relative to smaller theropods throughout the Late Triassic.

\section{Acknowledgments}

I thank S. Nesbitt and the Virginia Tech Paleobiology Research Group for insightful comments on drafts of this manuscript,
A. Marsh for photographs of Dilophosaurus, R. Irmis for photographs of Liliensternus, T. Culver of UCM and S. Lucas of NMMNH for access to collections, and A. Marsh, P. Olsen, R. Irmis, and K. Padian for discussion. I also thank R. Benson, M. Carrano, and one anonymous referee for their helpful reviews of this manuscript, which greatly improved its quality. TNT software was provided free of charge by the Willi Hennig Society. This study was supported by a National Science Foundation Graduate Research Fellowship. Funding for open access was provided by Cambridge University Press.

\section{Accessibility of supplemental data}

Data available from the Dryad Digital Repository: https://doi. org/10.5061/dryad.rh66vg2.

\section{References}

Alexander, R.M., 2006, Dinosaur biomechanics: Proceedings of the Royal Society B: Biological Sciences, v. 273, p. 1849-1855.

Arcucci, A., and Coria, R.A., 2003, A new Triassic dinosaur: Ameghiniana, v. 40, p. 217-228.

Bakker, R.T., 1986, The Dinosaur Heresies: New York, William Morrow, 482 p. Baron, M.G., Norman, D.B., and Barrett, P.M., 2017, A new hypothesis of dinosaur relationships and early dinosaur evolution: Nature, v. 543, p. 501-506.

Benson, R.B.J., Butler, R.J., Carrano, M.T., and O'Connor, P.M., 2012, Airfilled postcranial bones in theropod dinosaurs: Physiological implications and the 'reptile'-bird transition: Biological Reviews, v. 87, p. 168-193.

Benson, R.B.J., Campione, N.E., Carrano, M.T., Mannion, P.D., Sullivan, C., Upchurch, P., and Evans, D.C., 2014, Rates of dinosaur body mass evolution indicate 170 million years of sustained ecological innovation on the avian stem lineage: PLoS Biology, v. 12, p. e1001853.

Benson, R.B.J., Hunt, A.P., Carrano, M.T., and Campione, N., 2017, Data from: Cope's rule and the adaptive landscape of dinosaur body size evolution: Dryad Digital Repository, https://doi.org/10.5061/dryad.1t3r4.

Benson, R.B.J., Hunt, G., Carrano, M.T., and Campione, N., 2018, Cope's rule and the adaptive landscape of dinosaur body size evolution: Palaeontology, v. 61 , p. $13-48$.

Brusatte, S.L., Benton, M.J., Ruta, M., and Lloyd, F.T., 2008, Superiority, competition, and opportunism in the evolutionary radiation of dinosaurs: Science, v. 321, p. 1485-1488.

Brusatte, S.L., Nesbitt, S.J., Irmis, R.B., Butler, R.J., Benton, M.J., and Norell, M.A., 2010a, The origin and early radiation of dinosaurs: EarthScience Reviews, v. 101 , p. $68-100$.

Brusatte, S.L., Norell, M.A., Carr, T.D., Erickson, G.M., Hutchinson, J.R., Balanoff, A.M., Bever, G.S., Choiniere, J.N., Makovicky, P.J., and $\mathrm{Xu}, \mathrm{X} ., 2010$ b, Tyrannosaur paleobiology: New research on ancient exemplar organisms: Science, v. 329, no. 5998, p. 1481-1485.

Burch, S.H., 2014, Complete forelimb myology of the basal theropod dinosaur Tawa hallae based on a novel robust muscle reconstruction method: Journal of Anatomy, v. 225, p. 271-297.

Butler, R.J., and Zhao, Q., 2009, The small-bodied ornithischian dinosaurs Micropachycephalosaurus hongtuyanensis and Wannanosaurus yansiensis from the Late Cretaceous of China: Cretaceous Research, v. 30, p. 63-77.

Cabriera, S.G., et al., 2016, A unique Late Triassic dinosauromorph assemblage reveals dinosaur ancestral anatomy and diet: Current Biology, v. 26, p. 3090-3095.

Camp, C.L., 1936, A new type of small bipedal dinosaur from the Navajo Sandstone of Arizona: University of California Publications, Bulletin of the Department of Geological Sciences, v. 24, p. 39-56.

Campione, N.E., and Evans, D.C., 2012, A universal scaling relationship between body mass and proximal limb bone dimensions in quadrupedal terrestrial tetrapods: BMC Biology, v. 10, p. 1-21.

Campione, N., Brink, K.S., Freedman, E.A., and McGarrity, C.T., 2013, 'Glishades ericksoni', an indeterminate juvenile hadrosaurid from the Two Medicine Formation of Montana: Implications for hadrosauroid diversity in the latest Cretaceous (Campanian-Maastrichtian) of western North America: Palaeodiversity and Palaeoenvironments, v. 93, p. 65-75.

Campione, N., Evans, D.C., Brown, C.M., Carrano, M.T., 2014, Body mass estimation in non-avian bipeds using a theoretical conversion to quadruped stylopodial proportions: Methods in Ecology and Evolution, v. 5, p. 913-923.

Carpenter, K., 1997, A giant coelopysoid (Ceratosauria) theropod from the Upper Triassic of New Mexico, USA: Neues Jahrbuch für Geologie und Paläontologie, v. 205, p. 189-208. 
Carrano, M.T., 2006, Body-size evolution in the Dinosauria, in Carrano, M.T., Gaudin, T.J., Blob, R.W., and Wible, J.R., eds., Amniote Paleobiology: Perspectives on the Evolution of Mammals, Birds, and Reptiles: A Volume Honoring James Allen Hopson: Chicago, University of Chicago Press, p. $225-268$

Carrano, M.T., Hutchinson, J.R., and Sampson, S.D., 2005, New information of Segisaurus halli, a small theropod dinosaur from the Early Jurassic of Arizona: Journal of Vertebrate Paleontology, v. 25, p. 835-849.

Carrano, M.T., Benson, R.B.J., Sampson, S.D., 2012, The phylogeny of Tetanurae (Dinosauria: Theropoda): Journal of Systematic Palaeontology, v. 10, p. $211-300$

Cau, A., 2018, The assembly of the avian body plan: A 160-million-year long process: Bollettino della Società Paleontologica Italiana, v. 57, p. 1-25.

Christiansen, P., and Fariña, R.A., 2004, Mass prediction in theropod dinosaurs: Historical Biology, v. 16, p. 85-92.

Colbert, E.H., 1970, A saurischian dinosaur from the Triassic of Brazil: American Museum Novitates, v. 2405, p. 1-39.

Colbert, E.H., 1989, The Triassic dinosaur Coelophysis: Museum of Northern Arizona Bulletin, v. 57, p. 1-160.

Cope, E.D., 1887, The dinosaurian genus Coelurus: American Naturalist, v. 21, p. $367-369$.

Day, J.J., Normal, D.B., Upchurch, P., and Powell, H.P., 2002, Biomechanics: Dinosaur locomotion from a new trackway: Nature, v. 415, p. 494-495.

Erickson, G.M., Mackovicky, P.J., Currie, P.J., Norell, M.A., Yerby, S.A., and Brochu, C.A., 2004, Gigantism and comparative life-history parameters of tyrannosaurid dinosaurs: Nature, v. 430, p. 772-775.

Evans, D.C., Brown, C.M., Ryan, M.J., and Tsogtbaatar, K., 2011, Cranial ornamentation and ontogenetic status of Homalocephale calathocercos (Ornithischia: Pachycephalosauria) from the Nemegt Formation, Mongolia: Journal of Vertebrate Paleontology, v. 31, p. 84-92.

Ezcurra, M.D., 2006, A review of the systematic position of the dinosauriform archosaur Eucoelophysis baldwini Sullivan and Lucas, 1999 from the Upper Triassic of New Mexico, USA: Geodiversitas, v. 28, p. 649-684.

Ezcurra, M.D., 2017, A new early coelophysoid neotheropod from the Late Triassic of northwestern Argentina: Ameghiniana, v. 54, p. 506-538.

Ezcurra, M.D., and Brusatte, S.L., 2011, Taxonomic and phylogenetic reassessment of the early neotheropod dinosaur Camposaurus arizonensis from the Late Triassic of North America: Palaeontology, v. 54, p. 763-772.

Ezcurra, M.D., and Cuny, G., 2007, The coelophysoid Lophostropheus airelensis, gen. nov.: A review of the systematics of "Liliensternus" airelensis from the Triassic-Jurassic outcrops of Normandy (France): Journal of Vertebrate Paleontology, v. 27, p. 73-86

Ezcurra, M.D., and Novas, F.E., 2007, Phylogenetic relationships of the Triassic theropod Zupaysaurus rougieri from NW Argentina: Historical Biology, v. 19 , p. $35-72$.

Farlow, J.O., and Pianka, E.R., 2002, Body size overlap, habitat partitioning and living space requirements of terrestrial vertebrate predators: Implications for the paleoecology of large theropod dinosaurs: Historical Biology, v. 16, p. $21-40$.

Fowler, D.W., Woodward, H.N., Freedman, E.A., Larson, P.L., and Horner, J.R., 2011, Reanalysis of "Raptorex kriegsteini": A juvenile tyrannosaurid dinosaur from Mongolia: PLoS ONE, v. 6, p. e21376.

Gauthier, J., 1986, Saurischian monophyly and the origin of birds: Memoirs of the California Academy of Science, v. 8, p. 1-55.

Goloboff, P.A., and Catalano, S.A., 2016, TNT version 1.5, including a full implementation of phylogenetic morphometrics: Cladistics, v. 32, p. 221-238.

Griffin, C.T., 2018, Developmental patterns and variation among early theropods: Journal of Anatomy, v. 232, p. 604-640.

Griffin, C.T., in press, Pathological bone tissue in a Late Triassic neotheropod fibula, with implications for the interpretation of medullary bone: New Jersey State Museum Investigations, v. 6.

Griffin, C.T., and Nesbitt, S.J., 2016, Anomalously high variation in postnatal development is ancestral for dinosaurs but lost in birds: Proceedings of the National Academy of Sciences, USA, v. 113, p. 14757-14762.

Griffin, C.T., and Nesbitt, S.J., in press, Does the maximum body size of theropods increase across the Triassic-Jurassic boundary? Integrating ontogeny, phylogeny, and body size: The Anatomical Record.

Hammer, W.R., and Hickerson, W.J., 1994, A crested theropod dinosaur from Antarctica: Science, v. 264 , p. 828-830.

Holtz, T.R. J., 1994, The phylogenetic position of the Tyrannosauridae: Implications for theropod systematics: Journal of Paleontology, v. 68, p. $1100-1117$.

Huene, F.v., 1934, Ein neuer Coelurosaurier in der thüringischen Trias: Paläontologische Zeitschrift, v. 16, p. 145-170.

Hunt, A.P., 1994, Vertebrate paleontology and biostratigraphy of the Bull Canyon Formation (Chinle Group, Upper Triassic) with a revision of the families Metoposauridae (Amphibia: Temnospondyli) and Parasuchidae (Reptilia: Archosauria) [Ph.D. dissertation]: Albuquerque, University of New Mexico, $404 \mathrm{p}$.
Hunt, A.P., 2001, The vertebrate fauna, biostratigraphy and biochronology of the type Revueltian faunachron, Bull Canyon Formation (Upper Triassic), east-central New Mexico: New Mexico Geological Society Guidebook 52 , p. $123-152$.

Hunt, A.P., Lucas, S.G., Heckert, A.B., Sullivan, R.M., and Lockley, M.G., 1998, Late Triassic dinosaurs from the western United States: Géobios, v. 31, p. $511-531$

Irmis, R.B., 2011, Evaluating hypotheses for the early diversification of dinosaurs: Earth and Environmental Science Transactions of the Royal Society of Edinburgh, v. 101, p. 397-426.

Irmis, R.B., Nesbitt, S.J., Padian, K., Smith, N.D., Turner, A.H., Woody, D., and Downs, A., 2007, A Late Triassic dinosauromorph assemblage from New Mexico and the rise of dinosaurs: Science, v. 317, p. 358-361.

Ivie, M.A., Slipinski, S.A., Wegrzynowicz, P., 2001, Generic homonyms in the Colydiinae (Coleoptera: Zopheridae): Insecta Mundi, v. 15, p. 63-64.

Langer, M.C., 2003, The pelvic and hind limb anatomy of the stemsauropodomorph Saturnalia tupiniquim (Late Triassic, Brazil): PaleoBios, v. 23 , no. 2 , p. $1-30$.

Langer, M.C., and Benton, M.J., 2006, Early dinosaurs: A phylogenetic study: Journal of Systematic Palaeontology, v. 4, p. 309-358.

Langer, M.C., Abdala, F., Richter, M., and Benton, M., 1999, A sauropodomorph dinosaur from the Upper Triassic (Carnian) of southern Brazil: Comptes Rendus de l'Académie des Sciences, v. 329, p. 511-517.

Langer, M.C., Nesbitt, S.J., Bittencourt, J.S., and Irmis, R.B., 2013, Nondinosaurian Dinosauromorpha, in Nesbitt, S.J., Desojo, J.B., and Irmis, R.B., eds., Anatomy, Phylogeny, and Palaeobiology of Early Archosaurs and Their Kin: London, Geological Society Special Publications 379, p. 157-186.

Lee, M.S.Y., Cau, A., Naish, D., and Dyke, G.J., 2014, Sustained miniaturization and anatomical innovation in the dinosaurian ancestors of birds: Science, v. 345, p. 562-566.

Linnaeus, C., 1758, Systema Naturae per Regna Tria Naturae, Secundum Classes, Ordines, Genera, Species, cum Chararteribus, Differentiis, Synonymis, Locis Tomus 1: Regnum animale (tenth edition): Holmiae, Laurentii Salvii, 824 p.

Long, R.A., and Murry, P.A., 1995, Late Triassic (Carnian and Norian) tetrapods from the southwestern United States: New Mexico Museum Natural History Science Bulletin, v. 4, p. 1-254.

Lucas, S.G., 1998, Global tetrapod biostratigraphy and biochronology: Palaeogeography, Palaeoclimatology, Palaeoecology, v. 143, p. 347-384

Lucas, S.G., and Hunt, A.P., 1993, Tetrapod biochronology of the Chinle Group (Upper Triassic), western United States: New Mexico Museum of Natural History and Science Bulletin, v. 3, p. 327-329.

Maddison, W.P., and Maddison, D.R., 2016, Mesquite: A modular system for evolutionary analysis. Version 3.10, http://mesquiteproject.org.

Madsen, J.H., Jr., and Welles, S.P., 2000, Ceratosaurus (Dinosauria, Theropoda): A revised osteology: Utah Geological Survey Miscellaneous Publication, v. 00-2, p. 1-80.

Marsh, O.C., 1881, Principal characters of American Jurassic dinosaurs, Part V: The American Journal of Science, Series 3, v. 21, p. 417-423.

Marsh, O.C., 1884, Principal characters of American Jurassic dinosaurs, part VIII: The order Theropoda: American Journal of Science, ser. 3, v. 27, p. $329-340$.

Martill, D.M., Vidovic, S.U., Howells, C., and Nudds, J.R., 2016, The oldest Jurassic dinosaur: A basal neotheropod from the Hettangian of Great Britain: PLoS ONE, v. 11, p. e0145713.

Martinez, R.N., Sereno, P.C., Alcobar, O.A., Colombi, C.E., Renne, P.R., Montañez, I.P., and Currie, B. S., 2011, A basal dinosaur from the dawn of the dinosaur era in southwestern Pangaea: Science, v. 331, p. 206-210.

Molina-Garza, R.S., Geissman, J.W., Gomez, A., and Horton, B., 1993, Paleomagnetic data from Triassic strata, Zuni uplift, New Mexico: Further evidence of large-magnitude Triassic apparent polar wander of North America: Journal of Geophysical Research, v. 103, p. 24, 189-124, 200.

Nesbitt, S.J., 2011, The early evolution of archosaurs: Relationships and the origin of major clades: Bulletin of the American Museum of Natural History, v. 352 , p. $1-292$.

Nesbitt, S.J., and Ezcurra, M.D., 2015, The early fossil record of dinosaurs in North America: A new neotheropod from the base of the Upper Triassic Dockum Group of Texas: Acta Palaeontologica Polonica, v. 60, p. 513-526.

Nesbitt, S.J., Irmis, R.B., and Parker, W.G., 2007, A critical re-evaluation of the Late Triassic dinosaur taxa of North America: Journal of Systematic Palaeontology, v. 5, p. 209-243.

Nesbitt, S.J., Irmis, R.B., Parker, W.G., Smith, N.D., Turner, A.H., and Rowe, T., 2009, A complete skeleton of a Late Triassic saurischian and the early evolution of dinosaurs: Science, v. 326, p. 1530-1533.

Nesbitt, S.J., Sidor, C.A., Irmis, R.B., Angielczyk, K.D., Smith, R.M.H., and Tsuji, L.A., 2010, Ecologically distinct dinosaurian sister group shows early diversification of Ornithodira: Nature, v. 464, p. 95-98.

Nesbitt, S.J., Butler, R.J., Ezcurra, M.D., Barrett, P.M., Stocker, M.R., et al., 2017, The earliest bird-line archosaurs and the assembly of the dinosaur body plan: Nature, v. 544, p. 484-487. 
Novas, F.E., 1993, New information on the systematics and postcranial skeleton of Herrerasaurus ischigualastensis (Theropoda: Herrerasauridae) from the Ischigualasto Formation (Upper Triassic) of Argentina: Journal of Vertebrate Paleontology, v. 13, p. 400-423.

Novas, F.E., Ezcurra, M.D., Agnolin, F.L., Pol, D., and Ortíz, R., 2012, New Patagonian Cretaceous theropod sheds light about the early radiation of Coelurosauria: Revista del Museo Argentino de Ciencias Naturales, Nueva Serie, v. 14, p. 57-81.

O'Connor, P.M., 2007, The postcranial axial skeleton of Majungasaurus crenatissimus (Theropoda: Abelisauridae) from the Late Cretaceous of Madagascar: Journal of Vertebrate Paleontology Memoir, v. 8, p. 127-162.

Olsen, P.E., Kent, D.V., Sues, H.-D., Koeberl, C., Huber, H., Montanari, A., Rainforwth, E.C., Fowell, S.J., Szajna, M.J., and Hartline, B.W., 2002, Ascent of dinosaurs linked to an iridium anomaly at the Triassic-Jurassic boundary: Science, v. 296, p. 1305-1307.

Owen, R., 1842, Report on British fossil reptiles, Part II: Association for the Advancement of Science, 11th Meeting, v. 1841, p. 60-204.

Parker, W.G., and Martz, J.W., 2010, The Late Triassic (Norian) AdamanianRevueltian tetrapod faunal transition in the Chinle Formation of Petrified Forest National Park, Arizona: Earth and Environmental Science Transactions of the Royal Society of Edinburgh, v. 101, p. 231-260.

Parrish, J.M., and Carpenter, K., 1986, A new vertebrate fauna from the Late Triassic Dockum Formation of New Mexico, in Padian, K., ed., The Begin ning of the Age of Dinosaurs: New York, Cambridge University Press, p. $151-160$.

Preuschoft, H., Hohn, B., Stoinski, S., and Witzel, U., 2011, Why so huge? Biomechanical reasons for the acquisition of large size in sauropod and theropod dinosaurs, in Klein, N., Remes, K., Gee, C. T., and Sander, P. M., eds. Biology of the Sauropod Dinosaurs: Understanding the Life of Giants: Bloomington and Indianapolis, Indiana University Press, p. 195-216.

Puttick, M.N., Thomas, G.H., and Benton, M.J., 2014, High rates of evolution preceded the origin of birds: Evolution, v. 68, p. 1497-1510.

R Core Development Team, 2008, R: A language and environment for statistical computing: Vienna, Austria, R Foundation for Statistical Computing.

Raath, M.A., 1969, A new coelurosaurian dinosaur from the Forest Sandstone of Rhodesia: Arnoldia Rhodesia, v. 4, p. 1-25.

Raath, M.A., 1977, The anatomy of the Triassic theropod Syntarsus rhodesiensis (Sauischia: Podokesauridae) and a consideration of its biology [Ph.D. dissertation]: Grahamstown, South Africa, Rhodes University, 233 p.

Rauhut, O.W.M., 2003, The interrelationships and evolution of basal theropod dinosaurs: Special Papers in Palaeontology, v. 69, p. 1-214.

Rauhut, O.W.M., and Hungerbühler, A., 1998, A review of European Triassic theropods: Gaia, v. 15 , p. $75-88$

Reig, O.A., 1963, La presencia de dinosaurios saurisquios en los "Estratos de Ischigualasto" (Mesotriásico Superior) de las provincias de San Juan y La Rioja (República Argentina): Ameghiniana, v. 3, p. 3-20.

Revell, L.J., 2012, phytools: An R package for phylogenetic comparative biology (and other things): Methods in Ecology and Evolution, v. 3, p. 217-223

Rowe, T., 1989, A new species of the theropod dinosaur Syntarsus from the Early Jurassic Kayenta Formation of Arizona: Journal of Vertebrate Paleontology, v. 9, p. 125-136.

Rowe, T., and Gauthier, J., 1990, Ceratosauria, in Weishampel, D.B., Dodson, P., and Osmólska, H., eds., The Dinosauria: Berkeley, University of California Press, p. 151-168.

Ruta, M., Wagner, P.J., and Coates, M.I., 2006, Evolutionary patterns in early tetrapods. I. Rapid initial diversification followed by decrease in rates of character change: Proceedings of the Royal Society B: Biological Sciences, v. 273, p. 2107-2111.

Seebacher, F., 2001, A new method to calculate allometric length-mass relationships of dinosaurs: Journal of Vertebrate Paleontology, v. 21, p. 51-60.

Seeley, H.G., 1887, On the classification of the fossil animals commonly called Dinosauria: Proceedings of the Royal Society of London, v. 43, p. 165-171.

Sereno, P.C., and Novas, F.E., 1994, The skull and neck of the basal theropod Herrerasaurus ischigualastensis: Journal of Vertebrate Paleontology, v. 13 , p. $1137-1140$.
Sereno, P.C., Forster, C.A., Rogers, R.R., and Moneta, A.M., 1993, Primitive dinosaur skeleton from Argentina and the early evolution of the Dinosauria: Nature, v. 361, p. 64-66.

Sereno, P.C., McAllister, S., and Brusatte, S.L., 2005, TaxonSearch: A relational database for suprageneric taxa and phylogenetic definitions: PhyloInformatics, v. 8, p. 1-21.

Sereno, P.C., Tan, L., Brusatte, S.L., Kriegstein, H.J., Zhao, X., and Cloward, K., 2009, Tyrannosaurid skeletal design first evolved at small body size: Science, v. 326, p. 418-422.

Sereno, P.C., Martinez, R.N., and Alcobar, O.A., 2013, Osteology of Eoraptor lunensis (Dinosauria, Sauropodomorpha): Journal of Vertebrate Paleontology Memoir, v. 12, p. 83-179.

Smith, N.D., Makovicky, P.J., Hammer, W.R., and Currie, P.J., 2007, Osteology of Cryolophosaurus ellioti (Dinosauria: Theropoda) from the Early Jurassic of Antarctica and implications for early theropod evolution: Zoological Journal of the Linnean Society, v. 151, p. 377-421.

Sookias, R.B., Butler, R.J., and Benson, R.B.J., 2012, Rise of dinosaurs reveals major body size transitions are driven by passive processes of trait evolution: Proceedings of the Royal Society B: Biological Sciences, v. 279 , p. $2180-2187$.

Sorenson, M.D., 1999, TreeRot, Version 2: Boston, Boston University.

Sues, H.-D., Nesbitt, S.J., Berman, D.S., and Henrici, A.C., 2011, A late-surviving basal theropod dinosaur from the latest Triassic of North America: Proceedings of the Royal Society B: Biological Sciences, v. 278, p. 3459-3464.

Swofford, D.L., 2002, PAUP*. Phylogenetic Analysis Using Parsimony (*and Other Methods). Version 4: Sunderland, Massachusetts, Sinauer Associates.

Tsai, C.-H., and Fordyce, R.E., 2014, Disparate heterochronic processes in baleen whale evolution: Evolutionary Biology, v. 41, p. 299-307.

Tsuihiji, T., 2004, The ligament system in the neck of Rhea americana and its implication for the bifurcated neural spines of sauropod dinosaurs: Journal of Vertebrate Paleontology, v. 24, p. 165-172.

Tsuihiki, T., Watabe, M., Togtbaater, K., Tsubamoto, T., Barsbold, R., Suzuki, S Lee, A.H., Ridgley, R., Kawahara, Y., and Witmer, L.M., 2011, Cranial osteology of a juvenile specimen of Tarbosaurus bataar (Theropoda, Tyrannosauridae) from the Nemegt Formation (Upper Cretaceous) of Bugin Tsav, Mongolia: Journal of Vertebrate Paleontology, v. 31, p. 1-21.

Turner, A.H., and Nesbitt, S.J., 2013, Body size evolution during the Triassic archosauriform radiation, in Nesbitt, S.J., Desojo, J.B., and Irmis, R.B., eds., Anatomy, Phylogeny, and Palaeobiology of Early Archosaurs and Their Kin: London, Geological Society Special Publications 379, p. 573-597.

Tykoski, R.S., 1998, The osteology of Syntarsus kayentakatae and its implications for ceratosaurid phylogeny [M.S. thesis]: Austin, University of Texas, 217 p

Tykoski, R.S., 2005, Anatomy, ontogeny, and phylogeny of coelopysoid dinosaurs [Ph.D. dissertation]: Austin, University of Texas, 553 p.

Welles, S.P., 1954, New Jurassic dinosaur from the Kayenta formation of Arizona: Bulletin of the Geological Society of America, v. 65, p. 591-598.

Welles, S.P., 1984, Dilophosaurus wetherilli (Dinosauria, Theropoda) osteology and comparisons: Palaeontographica Abteilung A, v. 185, p. 85-180.

Wilson, J.A., 1999, A nomenclature for vertebral laminae in sauropods and other saurischian dinosaurs: Journal of Vertebrate Paleontology, v. 19, p. 639-653.

Wilson, J.P., Woodruff, D.C., Gardner, J.D., Flora, H.M., Horner, J.R., and Organ, C.L., 2016, Vertebral adaptations to large body size in theropod dinosaurs: PLoS ONE, v. 11, no. 7, p. e0158962.

Woodruff, D.C., 2014, The anatomy of the bifurcated neural spine and its occurrence within Tetrapoda: Journal of Morphology, v. 275, p. 1053-1065.

Yates, A.M., 2005, A new theropod dinosaur from the Early Jurassic of South Africa and its implications for the early evolution of theropods: Palaeontologia Africana, v. 41, p. 105-122.

You, H.-L., Azuma, Y., Wang, T., Wang, Y.-M., and Dong, Z.-M., 2014, The first well-preserved coelophysoid theropod dinosaur from Asia: Zootaxa, v. 3873 , p. $233-249$.

Accepted: 12 February 2019 